This item was submitted to Loughborough's Research Repository by the author.

Items in Figshare are protected by copyright, with all rights reserved, unless otherwise indicated.

\title{
Empowerment in project teams: a multi-level examination of the job performance implications
}

\section{PLEASE CITE THE PUBLISHED VERSION}

http://dx.doi.org/10.1080/01446190902729713

\section{PUBLISHER}

Routledge (@ Taylor \& Francis)

VERSION

AM (Accepted Manuscript)

\section{LICENCE}

CC BY-NC-ND 4.0

\section{REPOSITORY RECORD}

Tuuli, Martin Morgan, and Steve Rowlinson. 2019. "Empowerment in Project Teams: A Multi-level Examination of the Job Performance Implications". figshare. https://hdl.handle.net/2134/6657. 
This item was submitted to Loughborough's Institutional Repository (https://dspace.lboro.ac.uk/) by the author and is made available under the following Creative Commons Licence conditions.

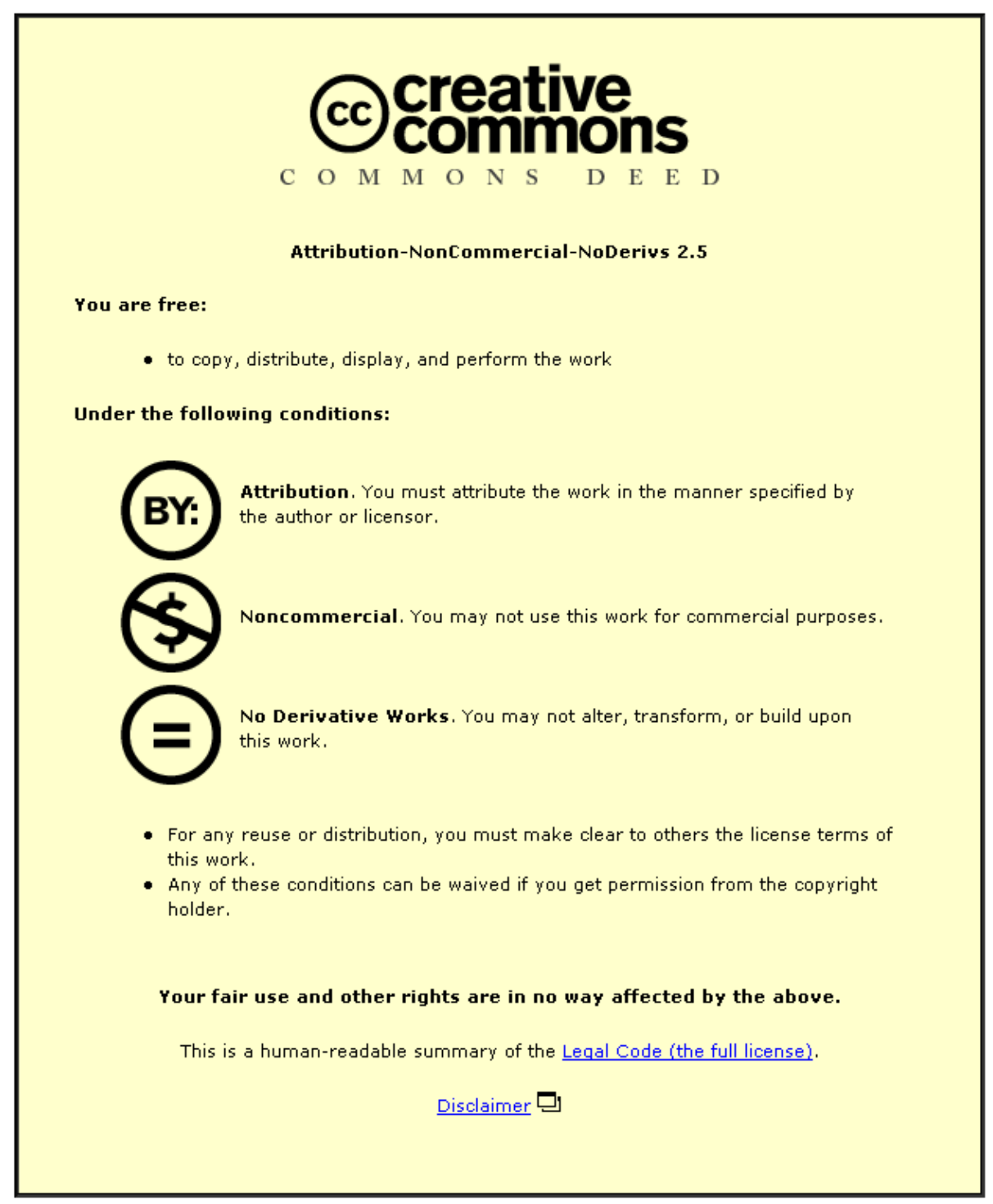

For the full text of this licence, please go to: http://creativecommons.org/licenses/by-nc-nd/2.5/ 


\title{
Empowerment in project teams: A multilevel examination
}

\section{of the job performance implications}

\author{
MARTIN MORGAN TUULI* and STEVE ROWLINSON \\ Department of Real Estate and Construction, The University of Hong Kong, 5F Knowles Building, \\ Pokfulam Road, Hong Kong
}

\begin{abstract}
An integrative multilevel model of empowerment and job performance behaviours is advanced, building on Social Cognitive Theory (SCT). Empowerment climate is hypothesized as influencing individual and team performance behaviours directly and partially through individual and team (psychological) empowerment. Using survey responses from 380 individuals, nested in 115 project management teams, we tested the direct, indirect and cross-level relationships delineated in the multilevel model, using a combination of OLS regression models and Hierarchical Linear Modelling (HLM). Empowerment climate positively related not only directly to both task and contextual performance behaviours but partially through both individual and team empowerment. At the team-level, empowerment climate also positively related directly to taskwork and teamwork behaviours and partially through team empowerment. The results suggest that empowerment climate and psychological empowerment play complementary roles in engendering individual and team performance behaviours and are therefore not mutually exclusive. The findings are also evident of convergence in management practices across cultures as well as different work context and further provide concrete targets of manipulation by organizations and leaders desirous of empowering individuals and teams in the project context.
\end{abstract}


Keywords: empowerment climate, Hierarchical Linear Modelling (HLM), job performance behaviours, psychological empowerment, social cognitive theory $(\mathrm{SCT})$.

\section{INTRODUCTION}

In dynamic and uncertain work environments such as construction projects, organizations are often faced with the daunting task of nurturing and sustaining highperformance in both individuals and teams, defined as two or more individuals who share common task objectives, perform interdependent tasks, and are mutually accountable for collective outcomes (Kozlowski and Bell, 2003). While the fundamental issues surrounding performance in construction have been identified as organizational and behavioural (Courtney and Winch, 2003, Slevin and Pinto, 2004), behaviour in particular, still remains an area of management concern that has not received much focus in construction industry related research (Cox et al., 2005). Yet, the sparse research efforts in this direction continue to highlight the significant impact of behaviour on project outcomes (e.g. Ahadzie et al., 2008, Anvuur, 2008, Phua, 2004). While behaviour in general is what people do in the course of their work, our interest here is in job performance behaviours, defined as the measurable behaviours that are relevant to the achievement of organizational goals (Campbell et al., 1993), and how such behaviours are influenced by empowerment.

Within the extant management literature, the concept of employee empowerment has emerged as key to engendering the performance of individuals and teams (c.f. Blanchard et al., 1999, Kanter, 1977, Kanter, 1993, Kirkman and Rosen, 1999, Kirkman et al., 2004, Liden et al., 2000, Spreitzer et al., 1997). Emerging empirical 
evidence within the construction project context also suggests that manager's powersharing behaviours are significantly related to project participant's motivation and performance (Liu and Fang, 2006); resonating prior findings of the productive nature of power-sharing and the appropriateness of such leadership behaviours and organizational practices in complex and uncertain work settings such as construction (c.f. Kanter, 1977). Empowered working is particularly deemed inherent in the way projects are run as autonomous profit centres (Loosemore et al., 2003), with the industry's project-oriented structure particularly providing a theoretically suitable context for the implementation of strategies consistent with employee empowerment (Dainty et al., 2002).

Research on empowerment and its outcomes have consistently been studied either at the individual-level (e.g. Liu et al., 2007, Spreitzer, 1995b, Spreitzer, 1996) or teamlevel (e.g. Kirkman and Rosen, 1999, Kirkman et al., 2004). In the latter, empowerment is conceived as a shared perception among individuals as distinct from the individual perception focus at the individual-level. Researchers have however yet to explicitly study empowerment as a multilevel concept at both the individual- and team-level, simultaneously, a notable exception being Chen et al (2007). This omission especially in team-based industries such as construction is particularly curious, given the potential theoretical and practical benefits of research into the interplay between individual and team empowerment, and how performance behaviours may be impacted at each level. Consequently, a multilevel perspective is taken to address the question: "what are the job performance implications of empowerment in project teams?" This question is examined using data from a sample of individuals nested in project management teams of construction organizations in Hong Kong. The study will therefore, hopefully, provide 
construction organizations with a path to enhancing the performance of the individuals and teams they deploy at the project level, and ultimately impact project outcomes.

In the section that follows, we advance an integrative, multilevel model of empowerment and job performance behaviours. First, we take a process view, which enables us to integrate two distinct perspectives of the empowerment concept; the structural and psychological perspectives. In doing so, we depict the structural perspective as the situational conditions (empowerment climate) that foster employee cognition of empowerment (psychological empowerment). We then explicate the theoretical and empirical basis of the link between empowerment and job performance behaviours. Social Cognitive Theory (SCT, Bandura, 1986, Bandura, 1977) provides an appropriate theoretical framework to weave together the process view of empowerment and job performance behaviours. Indeed, Dewettinck et al (2003) contend that applying such an interactionist lens could help in gaining a more profound understanding of how the empowerment process unfolds.

SCT explains human functioning in terms of a triadic model of dynamic interplay between the environment, individual cognitive state and behaviour. Interpolating this view in relation to empowerment and performance, environment becomes synonymous with empowerment climate, individual cognitive state with psychological empowerment and behaviour with job performance. Viewed in this manner, SCT suggests that previous studies that have taken either the structural (e.g. Liu et al, 2007; Liu and Fang, 2006) or psychological (e.g. Mathieu et al, 2006; Liden et al, 2000) perspective provide only a partial and incomplete picture of the empowerment process and how empowerment relates to behavioural outcomes. Thus, an interactional process is advocated, in which the perception of empowerment 
(psychological empowerment) is shaped through interaction with environmental factors (empowerment climate), to produce behavioural outcomes (job performance). Using this framework, we derive several hypotheses for testing in subsequent sections, and consequently outline the theoretical and practical implications of our findings.

\section{CONCEPTUAL MODEL AND HYPOTHESES}

Building on the SCT framework introduced above, we can delineate our multilevel conceptual model linking empowerment and performance behaviours at both the individual- and team-level, as depicted in Figure 1 below. In general, we propose that empowerment climate positively influences individual and team performance behaviours and does so partially through individual and team (psychological) empowerment. In the sub-sections that follow, we conceptualize empowerment climate, individual and team empowerment, as well as individual and team performance behaviours and explain the hypothesized linkages among these constructs as depicted in Figure 1.

\section{INSERT FIGURE 1 HERE}

\section{Empowerment Climate (Environment)}

The structural perspective of empowerment is rooted in the autonomy or influence afforded by the work environment (Wall et al., 2004). Accordingly, empowerment occurs through objective and structural organizational changes that grant individuals greater latitude to make decisions and exert influence regarding their work (Eylon and Bamberger, 2000, Kanter, 1977, Kanter, 1993, Liden and Arad, 1996). Seibert et 
al (2004) conceptualized structural empowerment as empowerment climate, representing the shared perceptions among organizational constituents of the organizational conditions that foster feelings of empowerment. Building on the work of Blanchard and his colleagues (Blanchard et al., 1999), Seibert et al (2004) further conceptualized empowerment climate as multi-dimensional comprising three organizational practices; information sharing, autonomy through boundaries and team accountability. This incidentally mirrors the early work of Kanter $(1977,1993)$ in which she identified six structural dimensions of the work environment as empowering; access to information, support, access to resources, opportunity to learn and grow, access to formal and informal power sources. We adopt Kanter's sixfactor model of empowerment climate which is supported by a large body of empirical evidence from the general management literature (e.g. Spreitzer, 1996, Eylon and Bamberger, 2000) and research in the healthcare sector in particular (e.g. Laschinger, 1996, Laschinger et al., 2001).

This notion of an empowerment climate is also consistent with Reichers and Schneider's (1990) proposal that "climate" be conceptualized and studied as a specific construct that has a particular referent or strategic focus, i.e. in terms of climate for something. Anderson and West (1998) also contend that three conditions are necessary for the development of a "climate"; (a) individual interaction, (b) existence of some common goal which predisposes individuals toward collective action, and (c) the existence of sufficient task interdependence. These are characteristic features of project teams and, thus, should support the development of shared perceptions regarding a climate for empowerment among project team members. 
Mills and Ungson (2003) however argue that the structural perspective of empowerment represents a "moral hazard dilemma" for managers, as its success or failure depends on the ability of managers to reconcile the potential inherent loss of control with the fundamental organizational need for goal congruence. This perspective of empowerment is also criticised for its failure to address the cognitive state of those being empowered. Thus, in some situations, power, knowledge, information and resources are shared, yet employees still evince disempowerment, and in other situations all the objective features of an empowering work climate are absent, yet employees feel and act empowered (Spreitzer and Doneson, 2008). These concerns cumulated in the development of the psychological perspective of empowerment.

\section{Individual Empowerment (Cognitive State)}

Psychological empowerment from an individual perspective is a constellation of experienced cognitions manifested as sense of meaning, competence, impact and self-determination (Thomas and Velthouse, 1990, Spreitzer, 1995a, Conger and Kanungo, 1988). Meaning is the congruence between one's values and the values associated with a task, work-unit or organization (Thomas and Velthouse, 1990). A typical manifestation of sense of meaningfulness within the project context is 'project affinity', "the commitment and attachment by stakeholders or participants to projects and their outcomes" (Dainty et al., 2005). Competence is the conviction that work activities can be carried out skilfully and successfully, and is analogous with Bandura's (1977) notion of self-efficacy. Self-determination is the belief that one is free to choose how to perform work activities. Impact reflects one's capacity to influence strategic, administrative and operational decisions within the organization or work-unit (Spreitzer, 1997). Spreitzer (1995a) contends that these four cognitions 
represent an active orientation to one's work role in which the individual is both willing and feels able to shape his or her work role and context. The four dimensions thus combine additively to create an overall gestalt of psychological empowerment so that, lack of any single dimension will deflate but not completely eliminate the overall degree of psychological empowerment (Spreitzer, 1995a).

The psychological perspective of empowerment is however criticised for ignoring substantive changes in organizational policies, practices and structures (Hardy and Leiba-O'Sullivan, 1998). Some critics also question its practical value, as organizations have little capacity to influence employee's inner workings to which psychological empowerment appeals (Forrester, 2000).

\section{Team Empowerment (Cognitive State)}

A consensus has emerged among researchers that psychological empowerment is an isomorphic construct (c.f. Kirkman and Rosen, 1997, Kirkman and Rosen, 1999, Spreitzer, 1996) and thus, retains the same basic meaning, structure and function across levels of analysis (Klein and Kozlowski, 2000, Chen et al., 2007). This multilevel view implies that psychological empowerment can manifest as an individual experience and a team or work-group experience (c.f. Kirkman and Rosen, 1997, Kirkman and Rosen, 1999, Mathieu et al., 2006). The notion of team empowerment can be traced to the sociotechnical movement at the Tavistock Institute and their work on autonomous work-groups. Team empowerment reflects 'team members' collective belief that they have the authority to control their proximal work environment and are responsible for the team's functioning" (Mathieu et al., 2006, p.98). Thus, in contrast to individual empowerment, team empowerment appeals to the shared feeling of team members regarding their collective level of empowerment, rather than the individual's perception of his own 
level of empowerment. Kirkman and Rosen (1997) take a multifaceted view and propose a four-dimensional structure of team empowerment comprising the team members' shared perception of potency, meaningfulness, autonomy and consequences. Potency is analogous to competence at the individual-level and reflects the collective belief of a group that it can be effective (Shea and Guzzo, 1987). It is also synonymous with Bandura's notion of collective-efficacy (Bandura, 1997). Meaningfulness is analogous to meaning and describes the shared beliefs of team members that their collective task is valuable and worthwhile. The autonomy dimension also corresponds to self-determination and is defined as the degree of freedom, independence and discretion that the team has regarding work schedule and work procedures (Hackman, 1987). Consequences, the fourth dimension of team empowerment, subsequently relabelled impact by Kirkman and Rosen (1999), is in line with its individual-level counterpart and reflects the team's belief that their collective task has significant consequences (Hackman, 1987). From the foregoing therefore, team empowerment and individual empowerment are related, yet represent conceptually distinct constructs. Thus, we hypothesize that;

H1a: Individual and team psychological empowerment are empirically distinct constructs.

\section{Linking Empowerment Climate and Psychological Empowerment}

\section{(Environment $\rightarrow$ Cognitive State)}

It is evident from the above conceptualisations that, empowerment climate and psychological empowerment (individual and team) are conceptually different in referent, focus and content. While empowerment climate refers to the work environment, psychological empowerment refers to an individual's cognitive state 
(Seibert et al., 2004). Further, empowerment climate assumes a relatively descriptive focus, while the focus of psychological empowerment is more subjective and evaluative. In terms of content, empowerment climate assesses shared perceptions of organizational structures and practices while psychological empowerment assesses the cognitive state of organizational members (Seibert et al., 2004). Consequently, we posit that;

H1b: Empowerment climate and psychological empowerment (individual and team) are empirically distinct constructs.

Although the structural and psychological perspectives of empowerment are conceptually distinct and provide different lenses for understanding empowerment in the work place (Spreitzer and Doneson, 2008), their complementarities are apparent from both theoretical and empirical perspectives (c.f. Tuuli and Rowlinson, 2007a, Tuuli and Rowlinson, 2007b). Thus, rather than being pursued separately, integrating them may provide a unifying explanation of the dynamics of the empowerment process (Menon, 2001, Mathieu et al., 2006). Indeed, a comparison of the criticisms of the psychological and structural perspectives shows that the strengths of each appear to make-up for the short comings of the other (c.f. Tuuli and Rowlinson, 2007a, Tuuli and Rowlinson, 2007b). Eylon and Bamberger (2000, p. 356) for instance point out that "it is just as difficult to view the construct as a cognition to be experienced independent of managerial action, as it is to view it as some objective shift in the structural characteristics of the organization that almost by definition 'enables' job incumbents".

Also, an antecedent role for empowerment climate is implicit in Conger and Kanungo's (1988, p. 474) conceptualization of empowerment as "a process of enhancing feelings of self-efficacy among organizational members through the 
identification of conditions that foster powerlessness and through their removal by both formal organizational practices and informal techniques providing efficacy information". Spreitzer (1995a) also explicitly linked the two perspectives when she suggested that, psychological empowerment comprises a set of cognitions shaped by the work environment. Liden and Arad (1996, p. 208) are unequivocal about the link when they also state that "psychological empowerment may be interpreted as the psychological outcome of structural changes designed to provide power". In support, Laschinger et al (2001) and subsequently Seibert et al (2004) recently found a positive and highly significant relationship between structural empowerment climate and psychological empowerment. Other researchers (e.g. Spreitzer, 1996, Eylon and Bamberger, 2000) have also examined the relationship between some dimensions of empowerment climate, as antecedents of psychological empowerment, and their findings corroborate earlier conceptual expectations.

Taken together then, in accord with SCT, empowerment reflects an interactive process between person and organizational environment in which the individual's feeling of empowerment (psychological empowerment) is either facilitated or inhibited by the subjective interpretations of salient, environmental events (empowerment climate). Thus, we posit that;

H2: Empowerment climate will be positively and significantly related to both (a) individual and (b) team empowerment.

\section{Individual and Team Performance Behaviours (Behaviour)}

There are two distinct perspectives to job performance; behavioural and outcome (Campbell et al., 1993, Sonnentag and Frese, 2002). The behavioural perspective defines job performance in terms of the measurable behaviours that are relevant to the achievement of organizational goals (Campbell et al., 1993). The outcome 
perspective refers to the objective consequences of behaviour (Sonnentag and Frese, 2002). Tying performance to behaviour rather than the distal outcomes of such behaviour however, has practical and conceptual advantages (Motowidlo, 2003), and the project context particularly provides a prima facie case for such a conceptualisation (c.f. Dainty et al., 2003). First, the behavioural perspective ensures that external factors (e.g. adverse weather conditions or poor design/estimates) which affect performance outcomes are excluded from the performance criteria of individuals and teams.

Second, from a managerial point of view, the behavioural approach has diagnostic advantages, as it allows early interventions by way of constructive feedback, to safeguard performance, rather than depending on outcomes which give no clues as to the underlying causes of poor or good performance (Motowidlo, 2003). Lastly, since the value of performance behaviours in this approach are evaluated in terms of expected consequences but not actual outcomes, job performance can be determined by measuring valuable behaviours without requiring information about the actual consequences of that behaviour (Motowidlo, 2003). This approach is particularly useful in assessing performance in the project setting where objective outcomes will not become known for several years until the project is actually completed.

Job performance is therefore conceptualized here as behaviours relevant to the achievement of organizational/project goals, in line with Campbell et al (1993), and Motowidlo (2003). This is also consistent with Dainty et al's (2003) call for a shift towards more balanced human performance criteria that consider the softer aspects of behaviour necessary for achieving project success. The multi-dimensional perspective of job performance is further adopted in which "task performance", valuable behaviours that contribute to the core technical activities of the 
organization/project, is distinguished from "contextual performance", behaviours that maintain and enhance the psychological, social and organizational context of work (Borman and Motowidlo, 1993).

From the above discussion, job performance is depicted invariably as an individuallevel phenomenon. The tendency to focus on the individual-level is perhaps not surprising since the logical assumption is that it is easiest to conceptualize as well as influence individual performance behaviours (DeNisi, 2000). However, the dependence of industries such as construction entirely on teams or work-groups for the accomplishment of tasks and organizational goals, suggests that performance behaviours at aggregate levels are equally important. In such work settings therefore, performance is increasingly being acknowledged as a multilevel construct that can manifest at the individual-, team- and even organizational-level- (DeNisi, 2000).

Although extrapolating the task and contextual behaviours dichotomy to the teamlevel may appear complex, it can be deciphered from the socio-technical systems theory view of groups (c.f. Trist et al., 1963). At the core of the theory is the premise that groups, organizations or other social aggregates are made up of technical and social sub-systems, whose joint optimisation leads to the achievement of unit goals. The technical sub-system comprises the transformation of raw materials into outputs, while the social sub-system links the human operators with the technology as well as with each other (Rousseau, 1977). This view is also consistently reflected in team process research (e.g. Stewart and Barrick, 2000), where team effectiveness or success has been shown to depend on two mechanisms; behaviours related to the task itself (technical) and behaviours that promote the socio-emotional context of the group (social). Hackman (1987) defines the socioemotional aspect in terms of the interpersonal transactions that take place within the 
group. Thus, from both the socio-technical and group process research points of view, one function of team performance is the social or socio-emotional aspect that essentially plays a facilitative or supportive role in task accomplishment. This aspect of team performance is often characterised as "teamwork", defined as "activities that serve to strengthen the quality of functional interactions, relationships, cooperation, communication and coordination of team members" (McIntyre and Salas, 1995). McIntyre and Salas (1995) further assert that teamwork is the composite of behavioural and attitudinal indicators of interaction among team members to reach common goals as well as adapt to team circumstances. Teamwork viewed in this manner, is therefore synonymous with Borman and Motowidlo's (1993) notion of contextual performance behaviours at the individual-level.

The other aspect of team performance evident from the sociotechnical system theory and group process research is the task or technical component. Hackman (1987) refers to this category as those aspects of interaction that relate directly to a group task. McIntyre and Salas (1995) also refer to this technical component as "taskwork", defined essentially as those activities of the team members that are related to the accomplishment of group technical operations. This view of taskwork as behaviours related to the task or technical sub-system that contributes to the operation of the technical core is thus analogous to Borman and Motowidlo's (1993) view of task performance behaviours at the individual-level.

Taken together, team performance can therefore be conceptualized as comprising "taskwork" and "teamwork" behaviours, with their corresponding individual-level analogues as task performance and contextual performance behaviours, respectively. Although clearly related, we posit that these represent conceptually distinct constructs. As Marks et al (2001, p. 357) point out "taskwork represents what it is 
that teams are doing, whereas teamwork describes how they are doing it with each other". Thus;

H3: Team (taskwork and teamwork) and individual (task and contextual) performance behaviours are empirically distinct constructs.

\section{Linking Empowerment Climate and Individual Performance Behaviours}

\section{$($ Environment $\rightarrow$ Behaviour $)$}

The view that employee behaviours are the outcome of their work environment has a long history (c.f. Litwin and Stringer, 1968). Indeed, this was the premise of Kanter's $(1977,1993)$ seminal work in which she identified access to information, support, access to resources, opportunity to learn and grow, access to formal and informal power sources as key elements of an empowering work climate. Kanter explicitly linked empowerment climate to performance behaviours when she opined that "except for factors more properly located outside of an organization's boundaries, there appear few instances of important aspects of individual behaviour and attributes that do not bear a relation to one or more of [the empowerment climate] variables" (Kanter, 1977, p. 246).

A closer examination of the constituent dimensions of empowerment climate makes the link more apparent. For example, access to information entails making more information about work, the organization's goals, strategies and plans more available or accessible and in a timely manner for all employees (Kanter, 1988). Employees with such information are able to make more informed decisions that are more aligned with organizational goals and initiate behaviours that promote task accomplishment. Support, manifested as active expression of faith in one's abilities, optimism and implicit encouragement (Eylon and Bamberger, 2000), is also expected to promote extra-role behaviours. Access to the resources required to get 
things done has also been identified as a key situational variable that inhibit or enhance performance (Peters and O'Connor, 1980). The performance implications of opportunity, representing the circumstances in which it is both possible to apply existing knowledge and to further develop that knowledge (Wall et al., 2002) are apparent. Employees in high opportunity jobs also tend to develop high aspirations, greater organizational commitment and thus are persistent in task accomplishment. Access to formal and informal power sources relates to "the capacity to mobilise resources" (Kanter, 1977, p. 247). These resources include information and support from organizational networks as well as materials and supplies. Kanter (1988) particularly refers to access to information, support and resources as the three indispensable power tools employees need to get their jobs done. Taken together then, we posit that;

H4: Empowerment climate will be positively and significantly related to both (a) task and (b) contextual performance behaviours.

\section{Linking Empowerment Climate and Team Performance Behaviours}

(Environment $\rightarrow$ Behaviour)

Empowerment climate is expected to have similar effects on taskwork and teamwork behaviours as in the case of task and contextual performance behaviours discussed above. For example, in a meta analysis of leadership behaviours, Burke et al (2006) found positive and significant relationships between empowering leadership behaviours and team effectiveness, team productivity and team learning. More specifically, Kirkman and Rosen (1999) contend that access to strategic information enables team members to determine appropriate courses of action towards task 
accomplishment. Conversely, lack of necessary information in team context increases uncertainty, and thereby makes it more difficult to take actions in such an interdependent context (Siegall and Gardner, 2000). Managerial and social support have also been identified as key determinants of effective team performance (Campion et al., 1996). In a related study, Thamhain (2004) found environmental factors, including support from units across organizational lines and opportunities for career development and advancement, to be strong correlates of team performance. Thus;

H5: Empowerment climate will be positively and significantly related to both (a) taskwork and (b) teamwork behaviours.

\section{Linking Individual Empowerment and Individual Performance Behaviours}

\section{(Cognitive State $\rightarrow$ Behaviour)}

A key presumption of empowerment theory is that empowered individuals perform better than those relatively less empowered (c.f. Thomas and Velthouse, 1990). The performance gains arise from the flexibility of being able to resolve problems at source, rather than escalating to specialists or senior management (Parker and Turner, 2002). This is consistent with the view that employees generally have a more complete knowledge and information about their work than top managers and are therefore better positioned to plan and schedule their work, as well as identify and resolve the obstacles that constrain their performance (Cooke, 1994).

Thomas and Velthouse (1990) particularly opined that when individuals feel empowered, proactive behaviours such as flexibility, resilience and persistence ensue. Thus, individuals who feel that their jobs are meaningful and that by completing their job responsibilities they have an impact on others within and outside of the organization, are motivated to perform well (Liden et al., 2000). 
Individuals who perceive they have the necessary job skills and can choose how to do their job also out-perform their counterparts who do not. Indeed, the effect of competence or self-efficacy on performance is reported as profound in the literature (c.f. Gist and Mitchell, 1992, Bandura, 1977, Bandura, 1986). Recently, Thamhain (2004) also found that the most significant drivers of performance in project teams were those related to the work itself as well as those supporting intrinsic professional needs. We therefore hypothesize that;

H6: Individual empowerment will be positively and significantly related to both (a) task and (b) contextual behaviours.

\section{Linking Team Empowerment and Team Performance Behaviours}

\section{(Cognitive State $\rightarrow$ Behaviour)}

Empowerment has been portrayed as an isomorphic construct (c.f. Kirkman and Rosen, 1997). Thus, team and individual empowerment are very similar in terms of underlying dimensions predictors and outcomes. Team empowerment will therefore have similar performance consequences as individual empowerment. For example, Shea and Guzzo (1987) contend that group potency or collective-efficacy determines the level of group performance through its effect on the extent to which group members apply resources and effort to group tasks. In support, Kirkman and Rosen (1999) found that the more team members experience team empowerment the more productive and proactive the team becomes. They also found more empowered teams to have higher levels of customer service. Thus, we hypothesize that;

H7: Team empowerment will be positively and significantly related to both (a) taskwork and (b) teamwork behaviours. 


\section{The Mediating Role of individual and Team Empowerment}

(Environment $\rightarrow$ Cognitive State $\rightarrow$ Behaviour)

While empowerment climate and psychological empowerment are both expected to directly relate to performance behaviours, the discussions regarding their interrelationship suggest that psychological empowerment may also be a mechanism through which empowerment climate impacts performance behaviours. This view is implicit in the theoretical expositions of both empowerment climate and psychological empowerment (c.f. Conger and Kanungo, 1988, Kanter, 1977, Liden et al., 2000, Spreitzer, 1995b, Spreitzer, 1996) and in particular work design theory, upon which the empowerment concept is deeply rooted. For example, Hackman and Oldham's (1976) job characteristic model posits that job characteristics (comprising, skill variety, task identity, task significance, autonomy and feedback) should enhance work performance through three psychological states (experienced meaningfulness, experienced responsibility and knowledge of results). The job characteristics and psychological states are, respectively, synonymous with empowerment climate and psychological empowerment.

This pattern of relationships is also consistent with the SCT view of the dynamic interplay among the environment, cognitive state and behaviour. Providing support for this theoretical expectation, Seibert et al (2004) found at the individual-level that psychological empowerment mediates the relationship between empowerment climate and individual performance, while Kirkman and Rosen (1999) found support for team-level mediation. Similarly, Chen et al (2007) found that both individual and team empowerment mediated the relationship between empowering leadership climate and both individual and team performance, respectively. Thus, we posit that; 
H8: Individual empowerment will partially mediate the positive relationship between empowerment climate and both (a) task and (b) contextual performance behaviours;

H9: Team empowerment will partially mediate the positive relationship between empowerment climate and both (a) task and (b) contextual performance behaviours;

H10: Team empowerment will partially mediate the positive relationship between empowerment climate and both (a) taskwork, and (b) teamwork behaviours.

\section{The Moderating Role of Team Psychological Empowerment}

(Environment $\rightarrow$ Cognitive State $\rightarrow$ Behaviour)

In high interdependent work settings such as construction projects, performance of one's role is not only a function of individual processes but also team processes, which can either facilitate or hinder individual performance (Chen and Kanfer, 2006). Because team empowerment triggers effective team processes (Chen and Kanfer, 2006), it may have attenuating effects on the influence of individual empowerment on individual performance behaviours by compensating for lower individual empowerment. Thus, when team empowerment is high, individuals will be expected to perform at high levels irrespective of the level of their individual empowerment as a result of the increased backup and improved communication and coordination from other team members (Chen et al., 2007). Providing support for this theoretical expectation, Chen et al (2007) found in high but not in low interdependence teams that when team empowerment is high the relation between 
individual empowerment and individual performance becomes less positive. Consequently, we posit that;

H11: Team empowerment moderates the influence of individual empowerment on both (a) task and (b) contextual performance behaviours; such that the influence of individual empowerment becomes less positive as team empowerment becomes more positive.

As a corollary then, we expect individual team members to be more motivated or confident to perform their own tasks when other members of their team share enthusiasm or believe they are capable of performing their tasks (Chen et al., 2007). Thus;

H12: Team empowerment will be positively and significantly related to both (a) task and (b) contextual behaviours.

\section{METHOD}

\section{Sample}

Project management teams of construction organizations in Hong Kong were the source of the data for the study. A comprehensive list of 526 key contact persons from 526 organizations (105 client, 158 consultant and 263 contractor organizations) was compiled for the data collection. Based partially on pre-test results and cost considerations, each contact person was mailed a questionnaire pack containing a cover letter, 5 questionnaires and 5 FREEPOST return envelopes. The first administration of the questionnaire yielded 232 responses (104 from contractors, 50 
from consultants and 78 from clients). A second administration to contact persons from whom one or no questionnaire was received in the first administration, yielded a further 150 responses (70 from contractors, 44 from consultants and 36 from clients), giving a total of 382 individual responses from 115 organizations (52 contractor, 34 client and 29 consultant), a 23\% response rate.

Upon examination of the responses, 39 respondents from 11 organizations initially classified as client organizations, indicated that they were working in dual roles as both client and consultant. This was subsequently confirmed by the contact persons. The sample sizes for the client and dual sub-groups are however small as a result (i.e. 75 and 39, respectively), precluding any meaningful sub-sample analysis. A missing data pattern analysis resulted in the exclusion of 2 responses for excessive missing data (>50\%) (c.f. Hair et al., 1998). The effective sample size for the analysis was therefore 380 individuals nested in 115 project management teams.

The double administration of the questionnaire also allowed for the checking of nonresponse bias, following Armstrong and Overton's (1977) time trend extrapolation procedure. The premise of this test is that differences between those who responded to the first administration and those who did in the second closely reflect differences between respondents to the survey and non-respondents. A comparison of the first and second administration respondents however, showed no significant differences in age $\left(\chi^{2}=3.75, d f=4, p>.441\right)$, gender $\left(\chi^{2}=.050, d f=1, p>.824\right)$, education $\left(\chi^{2}\right.$ $=7.46, d f=4, p>.113)$, nationality $\left(\chi^{2}=7.64, d f=6, p>.266\right)$ and organizational $\operatorname{rank}\left(\chi^{2}=3.50, d f=3, p>.321\right)$. While the presence of non-response bias cannot be completely ruled out, it can be inferred from the above results that the sample is representative of the population. 
Overall, 53\% of the respondents are older than 40 years, and $94 \%$ fall under the ranks of middle-management (40\%), senior management $(41 \%)$ and director level (13\%). This distribution corresponds favourably to the target population of management-level staff. Males make up $89 \%$ of the sample, nationals of Hong Kong and China combined make up $82 \%$ and persons of Chinese ethnicity make up $87 \%$. Average tenure in the construction industry is 17 years. In terms of education, $89 \%$ have a Bachelors degree or higher. Eighty-two percent of the organizations employ 50 or more people. The average management team size is 10 persons. Contractors tended to have much larger project management teams (average size of 12), about twice the average team size for consultant and client organizations. The average number of responses from the organizations was 4. Given that the average management team size of $10,40 \%$ of the management team members were sampled on the average, which is fairly representative.

\section{Measures}

Individual empowerment was measured with the 12-item scale developed by Spreitzer (1995a), which measures the 4 sub-dimensions; meaning, competence, selfdetermination and impact. Sample items include "The work I do is very important to me" for the meaning dimension and "I am confident about my ability to do my job" for competence.

Team empowerment was measured with Kirkman et al's (2004) 12-item scale, which measures the 4 sub-dimensions; potency, meaningfulness, autonomy and impact. Sample items include, "My team feels that its tasks are worthwhile" (meaningfulness) and "My team makes a difference in this organization" (impact). 
Empowerment climate was assessed with an adapted version of the copyright protected Conditions of Work Effectiveness Question-II (CWEQ-II) developed by Laschinger et al (2001). The written consent of Dr. Heather K. Spence Laschinger was sought in this regard. CWEQ-II is a 19-item scale comprising six sub-scales; access to opportunity, information, resources, support, formal power and informal power. The original scale items for opportunity, formal power and informal power were maintained. Access to support, information and resources sub-scales were replaced with equivalent ones developed by Spreitzer (1996) which have greater face validity.

Task performance behaviours were measured with a 6-item scale of employee inrole behaviours (IRB) developed by Williams and Anderson (1991). A sample item reads, "I adequately complete assigned duties".

Contextual performance behaviours were assessed with an adapted version of Van Scotter and Motowidlo's (1996) 15-item scale. Respondents indicated the likelihood of engaging in discretionary performance behaviours ranging from cooperative acts to self discipline acts in the course of performing their work role.

Taskwork behaviours were measured with an adapted 6-item scale developed by Kirkman and Rosen (1999). A sample item reads, "My team completes tasks on time".

Teamwork behaviours were measured with an adapted version of LePine et al (2000) 14-item scale covering interpersonal teamwork behaviours, organizational teamwork behaviours and task teamwork behaviours. Sample items include "My team members provide feedback and accept it from one another" for interpersonal teamwork, and 
"My team members accept team goals once accepted by the majority" for task teamwork.

All the above measures were anchored with a 5-point Likert scale. A number of control and demographic variables were also measured. At the individual-level, gender, age, educational, ethnicity, nationality and tenure were measured using single item questions. Organizational characteristics such as firm age and size were also measured.

Given the tendency for individuals to "fake good" in self-report surveys, we also measured social desirability using the 10-item short version of the Marlowe-Crowne 33-item scale of socially desirability (Crowne and Marlowe, 1960), proposed by Strahan and Gerbasi (1972). Respondents indicated "True" or "False" to five positively worded statements and five negatively worded statements, measuring two streams of behaviour; desirable but uncommon behaviours (e.g. practicing what one preaches) and undesirable but common behaviours (e.g. taking advantage of others). Sample items include, "I sometimes try to get even, rather than forgive and forget" (negative statement) and "I have never deliberately said something that hurt someone's feelings" (positive statement).

\section{Data Analysis Strategy}

Four categories of hypotheses are proposed for testing (see Figure 1). The first category requires the establishment of empirical distinctiveness (i.e. Hypotheses $\mathrm{H} 1 \mathrm{a}, \mathrm{b}$ and $\mathrm{H} 3$ ). The second and third categories propose single-level relationships between variables, respectively, at the individual-level (i.e. Hypotheses H6a,b) and team-level (i.e. Hypotheses H2b; H5a,b; H7a,b; H10a,b). The fourth proposes crosslevel relationships between variables at the team-level and variables at the 
individual-level (i.e. Hypotheses H2a; H4a,b; H9a,b; H10a,b; H11a,b and H12a,b). Thus, no single data analysis technique is appropriate for testing all the relationships. We used confirmatory factor analysis to test the first category of hypotheses and employed ordinary least square (OLS) regression to test the third category of singlelevel relationships at the team-level. The single-level relationships at the individuallevel and the cross-level relationships were analysed using Hierarchical Linear Modelling (HLM, Bliese and Hanges, 2004, Raudenbush and Bryk, 2002). HLM is the appropriate analysis technique for cross-level relationships and data that exhibits non-independence. Non-independence describes the degree to which responses of individuals are influenced by, depend on, or cluster by group membership due to social interaction or their arrangement spatially or sequentially in time (Kenny and Judd, 1986, Kenny and Judd, 1996). Ignoring non-independence leads to bias in significant tests (Kenny and Judd, 1986) and loss of power (Bliese and Hanges, 2004). Using HLM for cross-level relationships allows the simultaneous modelling of the team-level predictors (e.g. empowerment climate) and individual-level outcomes (e.g. task or contextual behaviours) without having to aggregate or disaggregate both the predictors and outcomes to one level (Seibert et al., 2004, Hofmann, 1997).

Baron and Kenny's (1986) three causal steps approach was also employed to test the mediated relationships (i.e. Hypotheses H8a,b; H9a,b and H10a,b). First (Step 1), the independent variable (i.e. empowerment climate) must be related to the outcome variable (i.e. task or contextual behaviours). Second (Step 2), the independent variable must be related to the mediator (i.e. individual or team empowerment). Third (Step 3), when the mediator is controlled for, the relationship between the independent variable and outcome variable becomes zero, for full mediation to be 
inferred, or is no longer significant or substantially reduces compared with that in the first step, for partial mediation to be inferred.

MacKinnon et al (2002) have recently suggested that Baron and Kenny's (1986) approach is too conservative, such that significant indirect effects may still exist even when Baron and Kenny's steps are not fully met. MacKinnon et al (2002) proposed testing the significance of the indirect effects in accordance with the propositions of Sobel (1982), which they found to provide a best balance of Type I error and statistical power. Sobel's (1982) approach calculates the indirect effect as the product of the coefficient of the independent variable in Step 2 of Baron and Kenny's approach and the coefficient of the mediator variable in Step 3. This indirect effect is then tested for statistical significance. Thus, the mediating role of individual and team empowerment (i.e. Hypotheses H8a,b; H9a,b and H10a,b) were also assessed with Sobel's test.

\section{RESULTS}

\section{Descriptive Statistics and Correlations}

The reliabilities and dimensionality of all multi-item measures were assessed by exploratory factor analysis using Principal Component Analysis with varimax rotation, as a preliminary measure to assert the validity of all multi-item measures used in the study. The scale items loaded as hypothesized or meaningfully and the measures also exhibited acceptable reliabilities as shown by their Chronbach's alphas in the diagonal of Table 1 below. Table 1 also shows the descriptive statistics and zero-order correlations among the variables. The pattern of correlations is consistent with the relationships delineated in the multilevel model depicted above. 
All correlations are below .80 , the threshold of very high correlations when multicollinearity is obvious (Field, 2005). To further reduce the potential effect of multicollinearity, all variables were grand-mean centred (c.f. Hofmann, 1997). The correlations between the social desirability measure and team type 1-contractor, taskwork behaviours and team empowerment variables are higher than the threshold of between -.20 and +.20 suggested by Mitchell and Jolley (Mitchell and Jolley, 2001), an indication that social desirability bias strongly influences these measures and thus warrants controlling for in the analyses.

\section{INSERT TABLE 1 HERE}

To justify aggregation of the team-level variables, James et al's (1984) interrater agreement index $\left(\mathrm{r}_{\mathrm{WG}(\mathrm{J})}\right)$ and Burke, Finkelstein and Dusig's (1999) Average Deviation indexes (i.e. $\mathrm{AD}_{\mathrm{M}(\mathrm{J})}$ and $\mathrm{AD}_{\mathrm{Md}(\mathrm{J})}$ ) were calculated using the $\mathrm{R}$ software (available at www.r-project.org). The results for each of the 4 team-level variables are shown in Table 1. Significance tests show that there is acceptable agreement among team members, supporting aggregation.

\section{Tests of Hypotheses}

For all individual- and cross-level analyses, age, gender, education, nationality, ethnicity, firm size and age, tenure and organization type as well as social desirability were included as control variables due to their possible confounding effects on the relationships (c.f. Dimitriades and Kufidu, 2004, Kanter, 1977, Spreitzer, 1995b, Spreitzer et al., 1997). Similarly, firm size and age, number of respondents per team, organization type and social desirability were also included as control variables in all team-level analyses. Given the large number of control variables, we examined the shared variance between the predictor variables of 
interest and the control variables in accord with Breaugh (2008), to check over control of predictor variance. The results show that only $7 \%$ of the variance in individual empowerment is shared with the control variables, $5 \%$ for empowerment climate and 3\% for team empowerment. This suggests that on average, $95 \%$ of the original construct is still reflected in the residual predictors. Thus, lack of construct validity from over control should not be an issue in the analyses.

\section{Tests of Hypotheses H1a,b}

To test the empirical distinctiveness of the 3 empowerment related constructs, the fit of a hypothesized model in which there were 3 second-order factors, corresponding to the 3 empowerment constructs, was compared with 2 alternative models, a 1 second-order factor model and a 2 second-order factor model. These tests were performed using the individual-level data which had a greater power, and also because individual perceptions (rather than shared perceptions among team members) of empowerment climate and team empowerment are likely to be more highly related to individual empowerment, making the individual-level tests more conservative (c.f. Chen et al., 2007). The analyses were performed using Amos 16.0 statistical analysis package.

To assess the 3 models, the observed variables (scale items) for each of the empowerment constructs were first specified to load onto their respective first-order factors (dimensions). In the first model, the 6 first-order factors (dimensions) of empowerment climate (access to information, resources, opportunity, support, informal and formal power), the 4 first-order factors of team empowerment (meaningfulness, impact, autonomy and potency) as well as the 4 first-order factors of individual empowerment (meaning, impact, self-determination and competence) 
were specified to load onto their respective second-order factors (constructs). The 2 alternative models were then specified in which all the 14 first-order factors were specified to load onto a 1 and then a 2 second-order factor model. The results show that the hypothesized three-factor model fits the data well, $\chi^{2}(1017, N=380)=$ 2895.97, comparative fit index $(\mathrm{CFI})=.88$, root-mean-square error of approximation $($ RMSEA $)=.07$. As expected, the alternative model in which all 14 dimensions loaded onto 1 second-order factor, fit the data significantly worse, $\Delta \chi^{2}(3, N=380)=$ 287.23, $p<.00, \mathrm{CFI}=.86, \mathrm{RMSEA}=.08$, as does the second alternative model, the two-factor solution, $\Delta \chi^{2}(2, N=380)=104.89, p<0.00, \mathrm{CFI}=.87, \mathrm{RMSEA}=.07$. Taken together, the results support Hypotheses H1a and H1b.

\section{INSERT TABLE 2 HERE}

\section{Tests of Hypotheses H2a and H2b}

Hypotheses $\mathrm{H} 2$ stated that empowerment climate will be positively and significantly related to both (a) individual and (b) team empowerment. Prior to testing Hypothesis H2a (a cross-level relationship), we ran a null model (i.e. a model without predictors, a requisite step in HLM analysis to decompose the variance in the outcome variable) with individual empowerment as the dependent variable, (i.e. model $1 a$ in Table 2) using the mixed models option for HLM in SPSS 16.0. The results provide evidence of significant within-team $\left(\sigma^{2}=.47, p<.001\right)$ and between-team $\left(\tau_{00}=.08, p<.01\right)$ variance in individual empowerment. This information also enables the calculation of the Interclass Correlation Coefficient (ICC), a measure of non-independence and thus, an indication of the proportion of the variance in the dependent variable that is attributable to team membership. The calculation gives an ICC of .17 (or 17\% of 
variance), confirming the presence of non-independence in the observations and justifying the use of HLM to test this hypothesis and thereby overcome the associated problems.

We then ran model $1 b$ (Table 2 ) with only the control variables as predictors. Gender $(B=-.26, \mathrm{p}<.05)$ and firm size $(B=.28, \mathrm{p}<.01)$ significantly predict individual empowerment. An examination of the zero-order bivariate correlations (see Table 1) however, show that gender and individual empowerment are not significantly related $(r=.08, n s)$ while firm size and individual empowerment are actually negatively and significantly related $(r=-.19, p<.001)$. This suggests that the regression findings pertaining to the effects of gender and firm size on individual empowerment may be spurious as a result of suppressor effects. The spurious nature of the regression findings on gender effects is the classical suppression scenario (c.f. Courville and Thompson, 2001; Cramer, 2003; Maassen and Bakker, 2001, Cohen and Cohen, 1983), where an independent variable (the suppressor) has no association with the independent variable but correlates positively with other independent variables in the model thereby acquiring a negative regression coefficient when entered together in the same model. The case of firm size is the negative or net suppression scenario (Cohen and Cohen, 1983; Tabachnick and Fidell, 2001), where the sign of the regression weight of the independent variable is the opposite of what should be expected on the basis of the correlation with the dependent variable. Although suppression improves predictive power, no explanatory benefits are gained (Anvuur, 2008; Tabachnick and Fidell, 2001). Thus, in interpreting the results in such circumstances greater weight is normally placed on the zero-order correlation (Courville and Thompson, 2001; Cramer, 2003). Based on this logic therefore, the significant regression findings for the link between both gender and firm size and 
individual empowerment are rejected for being spurious. Although the control variables together account for $7 \%$ of the variance in individual empowerment (lower part of Table 2), no significant finding in terms of any single control variable is discernable. Finally, we estimated model $1 c$ to directly test Hypothesis H2a. The results indicate a highly significant relationship between empowerment climate and individual empowerment $(B=.77, p<.001)$. Empowerment climate also explains a unique variance of $42 \%$ in individual empowerment. Thus, Hypothesis $\mathrm{H} 2 \mathrm{a}$ is supported.

\section{INSERT TABLE 3 HERE}

To test Hypothesis H2b (a team-level relationship), we used the OLS regression option in SPSS 16.0. We first ran model $2 a$ (Table 3) with only the control variables as predictors. Only social desirability $(B=.09, p<.01)$ significantly predict team empowerment and together with the other control variables explain only $5 \%$ of variance. We then ran model $2 b$ (Table 3) to test Hypothesis H2b. The results indicate a highly significant relationship between empowerment climate and team empowerment $(B=.70, p<.001)$. Empowerment climate also explains a unique variance of $46 \%$ in team empowerment. Thus, Hypothesis H2b is also supported.

\section{Test of Hypothesis H3}

Hypothesis $\mathrm{H} 3$ posited that team (taskwork and teamwork) and individual (task and contextual) performance behaviours are empirically distinct constructs. To test this hypothesis, the fit of a hypothesized model in which there were 4 first-order factors corresponding to the 4 performance behaviours, was compared with 3 alternative models, a one-factor model and 2, two-factor models. In the first two-factor solution, both teamwork and taskwork behaviours were specified to load onto a 
single factor and the contextual and task performance behaviours were also specified to load onto a single factor (team versus individual performance). In the second twofactor solution, teamwork and contextual behaviours loaded on a single factor and taskwork and task performance behaviours also loaded on a single factor (in-role versus extra-role performance).

In the first model, the 15 dimensions of teamwork, the 6 dimensions of taskwork, the 6 dimensions of task performance as well as the 15 dimensions of contextual performance behaviours were specified to load onto their respective first-order factors. The comparative fit of the 3 alternative models as discussed above were then assessed. The results show that the hypothesized four-factor model fits the data well, $\chi^{2}(813, N=380)=3077.09$, comparative fit index $(\mathrm{CFI})=.85$, root-mean-square error of approximation (RMSEA) $=.09$. As expected, the alternative models fit the data significantly worse: one-factor model, $\Delta \chi^{2}(6, N=380)=2367.03, p<0.00$, CFI $=.69$, RMSEA $=.12$; first two-factor model (team versus individual performance), $\Delta \chi^{2}(5, N=380)=1026.57, p<0.00, \mathrm{CFI}=.78, \mathrm{RMSEA}=.10$; second two-factor model (in-role versus extra-role performance), $\Delta \chi^{2}(5, N=380)=2007.08, p<0.00$, $\mathrm{CFI}=.71, \mathrm{RMSEA}=.12$. Taken together therefore, Hypothesis $\mathrm{H} 3$ is supported

\section{INSERT TABLE 4 HERE}

\section{Tests of Hypotheses $\mathrm{H} 4 \mathrm{a}$ and $\mathrm{H} 4 \mathrm{~b}$}

Hypotheses H4 posited that empowerment climate will be significantly and positively related to both (a) task and (b) contextual performance behaviours. Prior to testing Hypotheses $\mathrm{H} 4 \mathrm{a}$ and $\mathrm{H} 4 \mathrm{~b}$ (cross-level relationships), we ran two null models with task and contextual behaviours as the dependent variables, (i.e. models $3 a$ and $4 a$ in Table 4 , respectively). The results provide evidence of significant 
within-team and between-team variance in both task performance behaviours $\left(\sigma^{2}=\right.$ $\left..55, p<.001 ; \quad \tau_{00}=.09, p<.01\right)$ and contextual performance behaviours $\left(\sigma^{2}=.45, p\right.$ $<.001 ; \tau_{00}=.09, p<.01$ ). This gives an ICC of .14 (or $14 \%$ of variance) for task behaviours and .17 (or 17\% of variance) for contextual behaviours, confirming the presence of non-independence in the observations and justifying the use of HLM.

We then ran models $3 b$ and $4 b$ (Table 4) with only the control variables as predictors. In model $3 b$, only gender $(B=-.37, p<.01)$, team type 2 -client $(B=-.38$, $p<.01)$ and social desirability $(B=.09, p<.01)$ significantly predict task behaviours. Similarly, gender $(B=-.34, p<.01)$ and social desirability $(B=.08, p<$ $.01)$ significantly predict contextual behaviours in model $4 b$ (Table 4). However, an examination of the zero-order bivariate correlations (see Table 1) show that gender is actually positively and significantly related task behaviours $(r=.12, p<.05)$ but has no significant association with contextual behaviours $(r=.10, n s)$. Also, team type 2-client has no significant association with task behaviours $(r=.07, n s)$. The above regression findings involving gender and team type 2-client are therefore symptomatic of suppression effects as discussed earlier and thus, are rejected. The significant finding in terms of the control variables therefore, is that involving the social desirability measure and suggests that the levels of both task and contextual behaviours reported are affected by the respondent's propensity to fake good or bad, justifying the decision to control for its effects. The results also show that the control variables together account for only $6 \%$ of the variance in task behaviours and $4 \%$ of the variance in contextual behaviours (lower part of Table 4). Finally, we estimated models $3 c$ and $4 c$ to directly test Hypotheses $\mathrm{H} 4 \mathrm{a}$ and $\mathrm{H} 4 \mathrm{~b}$, respectively. The results indicate highly significant relationships between empowerment climate and both task $(B=.74, p<.001)$ and contextual $(B=.83, p<.001)$ performance behaviours. 
Empowerment climate also explains a unique variance of $36 \%$ in task behaviours and $61 \%$ in contextual behaviours (lower part of Table 4). Thus, Hypotheses H4a and $\mathrm{H} 4 \mathrm{~b}$ are supported.

\section{INSERT TABLE 5 HERE}

\section{Tests of Hypotheses H5a and H5b}

Hypotheses H5 posited that empowerment climate will be positively and significantly related to both (a) taskwork and (b) teamwork behaviours. To test this hypotheses (team-level relationships), we first ran models $5 a$ and $6 a$ (Table 5) with only the control variables as predictors and, taskwork and teamwork, respectively, as the dependent variables. Only social desirability significantly predicts taskwork behaviours $(B=.10, p<.01)$ while none of the control variables significantly predict teamwork behaviours but, respectively, explain $8 \%$ and $2 \%$ of the variance in taskwork and teamwork behaviours. We then ran models $5 b$ and $6 b$ (Table 5) to test Hypotheses $\mathrm{H} 5 \mathrm{a}$ and $\mathrm{H} 5 \mathrm{~b}$, respectively. The results indicate highly significant relationships between empowerment climate and both taskwork $(B=.72, p<.001)$ and teamwork $(B=.61, p<.001)$. Empowerment climate also explains a unique variance of $37 \%$ in taskwork behaviours and $32 \%$ in teamwork behaviours. Thus, Hypotheses H5a and H5b are both supported.

\section{Tests of Hypotheses H6a and H6b}

Hypotheses H6 posited that individual empowerment will be significantly and positively related to both (a) task and (b) contextual performance behaviours. The confirmation of non-independence in both task and contextual behaviours in the test of Hypotheses $\mathrm{H} 4 \mathrm{a}$ and $\mathrm{H} 4 \mathrm{~b}$ above also justifies the use of HLM to test these individual-level hypotheses. Thus, we estimated models $3 d$ and $4 d$ (Table 4 ) and the 
results indicate highly significant relationships between individual empowerment and both task $(B=.81, p<.001)$ and contextual $(B=.75, p<.001)$ performance behaviours. Individual empowerment also explains a unique variance of $46 \%$ in task behaviours and $42 \%$ in contextual behaviours (lower part of Table 4). Thus, Hypotheses H6a and H6b are supported.

\section{Tests of Hypotheses $H 7 a$ and $H 7 b$}

Hypotheses $\mathrm{H} 7$ posited that team empowerment will be positively and significantly related to both (a) taskwork and (b) teamwork behaviours. We ran models $5 c$ and $6 c$ (Table 5) to test Hypotheses $\mathrm{H7a}$ and $\mathrm{H} 7 \mathrm{~b}$ (team-level relationships). The results indicate highly significant relationships between team empowerment and both taskwork $(B=.93, p<.001)$ and teamwork $(B=.69, p<.001)$. Team empowerment also explains a unique variance of $61 \%$ in taskwork behaviours and $42 \%$ in teamwork behaviours. Thus, Hypotheses $\mathrm{H} 7 \mathrm{a}$ and $\mathrm{H} 7 \mathrm{~b}$ are both supported.

\section{Tests of Hypotheses H8a and H8b}

Hypotheses H8 stated that, individual empowerment will partially mediate the positive relationship between empowerment climate and both (a) task and (b) contextual performance behaviours. Baron and Kenny's (1986) three-step approach and Sobel's (1982) test of significance of the indirect effect as described earlier, were used to test these hypotheses. The free online Sobel's test calculator developed by Preacher and Leonardelli (2001) was used to test the significance of the indirect effects. Table 6 summarises the HLM results for Baron and Kenny's (1986) Step 3, while Table 7 summarises the results for Sobel's tests. The confirmation of Hypotheses H4 and H2a above, respectively, satisfy Steps 1 and 2. Model 7a (Table 6) shows that when empowerment climate and individual empowerment are simultaneously entered (Step 3), they both significantly predict task behaviours $(B=$ 
$.29, p<.001$ for empowerment climate and $B=.60, p<.001$ for individual empowerment), with the regression coefficient for empowerment climate dropping by $61 \%$, from $B=.74$ in Step 1 to $B=.29$. In addition, Sobel's tests shows that empowerment climate has a highly significant indirect effect on task behaviours through its positive relationship with individual empowerment (see upper part of Table 7), supporting Hypothesis H8a.

Model $8 a$ (Table 6) also shows that when empowerment climate and individual empowerment are simultaneously entered (Step 3), they both significantly predict contextual performance behaviours $(B=.61, p<.001$ for empowerment climate and $B=.29, p<.001$ for individual empowerment), with the regression coefficient for empowerment climate dropping by $27 \%$, from $B=.83$ in Step 1 to $B=.61$. Sobel's test further confirms that empowerment climate has a significant indirect effect on contextual behaviours through its positive relationship with individual empowerment (see upper part of Table 7). Thus, Hypothesis H8b is also supported.

\section{INSERT TABLE 6 HERE}

\section{Tests of Hypotheses H9a and H9b}

Hypotheses $\mathrm{H} 9$ also stated that team empowerment will partially mediate the positive relationship between empowerment climate and both (a) task and (b) contextual performance behaviours. The same approach as in Hypothesis 8 above was employed to tests these hypotheses. The confirmations of Hypotheses H4 and H2b above, respectively, satisfy Steps 1 and 2. Model $7 b$ (Table 6) also shows that when empowerment climate and team empowerment are simultaneously entered (Step 3), empowerment climate significantly predicts task behaviours $(B=.23, p<$ $.01)$, and so does team empowerment $(B=.60, p<.001)$. The regression coefficient 
for empowerment climate also dropped by $69 \%$ from $B=.74$ in Step 1 to $B=.23$. Sobel's test also confirms the significance of the indirect effect (see middle of Table 7). Thus, Hypothesis H9a is supported.

Model $8 b$ (Table 6) also shows that when empowerment climate and team empowerment are simultaneously entered (Step 3), they both significantly predict contextual performance behaviours $(B=.59, p<.001$, for empowerment climate and $B=.28, p<.001$, for team empowerment), with the regression coefficient for empowerment climate dropping by $29 \%$, from $B=.83$ in Step 1 to $B=.59$. In addition, Sobel's test is also significant (see middle of Table 7). Thus, Hypothesis $\mathrm{H} 9 \mathrm{~b}$ is supported.

\section{Tests of Hypotheses H1Oa and H1Oa}

Hypotheses H10 further stated that team empowerment will partially mediate the positive relationship between empowerment climate and both (a) taskwork, and (b) teamwork behaviours. The same approach as in Hypotheses 8 and 9 above were employed to test these hypotheses, but using OLS regression. The confirmation of Hypotheses H5 and H2b above, respectively, satisfy Steps 1 and 2. Model $5 d$ (Table 5) also shows that when empowerment climate and team empowerment are simultaneously entered (Step 3), empowerment climate does not significantly predict taskwork behaviours $(B=.15, n s)$, while team empowerment significantly predicts taskwork behaviours $(B=.82, p<.001)$. The regression coefficient for empowerment climate also dropped by $79 \%$ from $B=.72$ in Step 1 to $B=.15$. Sobel's test also confirms the significance of the indirect effect (see lower part of Table 7). Thus, Hypothesis H10a is supported. 
Model $6 d$ (Table 5) also shows that when empowerment climate and team empowerment are simultaneously entered (Step 3), they both significantly predict teamwork behaviours $(B=.26, p<.01$, for empowerment climate and $B=.50, p<$ .001 , for team empowerment), with the regression coefficient for empowerment climate dropping by $57 \%$, from $B=.61$ in Step 1 to $B=.26$. In addition, Sobel's test is also significant (see lower part of Table 7). Thus, Hypothesis H10b is also supported.

\section{INSERT TABLE 7 HERE}

\section{Tests of Hypotheses H1la and H11b}

Hypotheses H11 posited that team empowerment moderates the influence of individual empowerment on both (a) task and (b) contextual performance behaviours; such that the influence of individual empowerment becomes less positive as team empowerment becomes more positive. To test these hypotheses (cross-level relationships), we entered individual and team empowerment as well as their interaction term as predictors (models $7 c$ and $8 c$ of Table 6), with the significance of the interaction term as test of the hypotheses. The results show that the interaction term neither significantly predicts task behaviours $(B=-.02, n s)$, nor contextual behaviours $(B=-.03, n s)$, although the relationships are in the direction as posited. Taken together, Hypotheses H11a and H11b are both not supported.

\section{Tests of Hypotheses H12a and H12b}

Hypotheses $\mathrm{H} 12$ posited that team empowerment will be significantly and positively related to both (a) task and (b) contextual performance behaviours. We estimated models $3 e$ and $4 e$ (Table 4) to directly test Hypotheses H12a and H12b, respectively (cross-level relationships). The results indicate highly significant relationships 
between team empowerment and both task $(B=.79, p<.001)$ and contextual $(B=$ $.76, p<.001)$ performance behaviours. Team empowerment also explains $44 \%$ of the variance in task behaviours and $48 \%$ in contextual behaviours (lower part of Table 4). Thus, Hypotheses H12a and H12b are supported.

\section{Diagnostics}

We ran three sets of diagnostic checks for misspecification and to assert the goodness of fit of all the substantive HLM models. The level-1 and level-2 residuals were checked, respectively, for normal and multivariate normal distribution (Bickel, 2007) and they all showed no signs of departure from normality. We also checked whether the level-1 and level-2 residuals are uncorrelated and have a uniform variance (Bickel, 2007). Scatter plots of the level 1 and 2 residuals showed no signs of significant correlations. Lastly, we compared the fit (deviance) of the substantive models with that of the controls-only and null models (Bickel, 2007, Luke, 2004). The substantive models all fit the data significantly better than the two alternative models as shown by the change in deviance parameters (lower part of Tables 2, 4 and 6). Taken together, all the diagnostics confirm proper specification and goodness of fit of the HLM models.

For all the OLS regression models, we ran four diagnostic checks; linearity of the phenomenon measured, constant variance of the error terms, independence of the error terms, normality of the error term distribution (Field, 2005, Hair et al., 1998). We checked linearity and constant variance of the error terms by scatter plots of the standardised residuals against the predicted values (Hair et al., 1998) and used histogram plots to check the normality of the error term distribution. The plots showed no signs of departure from normality. We also checked the independence of error terms using the Durbin-Watson Test (Field, 2005). For uncorrelated error 
terms, the test statistic should be around 2. As shown in the lower part of Tables 3 and 5, the values range between 1.90 and 2.15, confirming the independence of the error terms. The ANOVA tests ( $F$-statistic) of how well the substantive models fit the data are also all significant (lower part of Tables 3 and 5). Taken together, the diagnostic checks for the OLS regression models also confirm good specification and fit.

\section{DISCUSSION AND CONCLUSIONS}

Social cognitive theory (SCT) provided an appropriate framework to integrate empowerment climate, psychological empowerment and job performance behaviours from a multilevel perspective and to subsequently test the resulting relationships. The literature on empowerment has long acknowledged that the structural and psychological perspectives are distinct. Yet, this distinction has hardly been put to empirical test, an exception being the recent efforts of Seibert et al (2004). Our results lend empirical support to the theoretical distinctiveness of empowerment climate and psychological empowerment but also confirm that the experience of empowerment can be fostered by an empowering work climate. This is supported by the substantial variance that empowerment climate accounted for in both individual empowerment (42\%) and team empowerment (46\%). The results further suggest that such a work climate can be created through the provision of access to information, support, resources, opportunity to learn and grow as well as access to formal and informal sources of power (Eylon and Bamberger, 2000, Kanter, 1977, Kanter, 1993).

Our results also confirm that taskwork and teamwork behaviours are empirically distinct from their individual analogues of task and contextual behaviours. This is an 
important finding, and suggests that individuals differentiate between behaviours that contribute to the fulfilment of their own tasks and those that help the team as a whole fulfil its collective goals. This is particularly important because the lack of common grounding in cross-functional project teams suggests that team members can often not cover for one another. Thus, team members are often personally responsible for adequately representing and integrating their technical contributions into the final product (Uhl-Bien and Graen, 1998), the construction of a building, road or bridge. Thus, promoting task and contextual behaviours will help team members fulfil their personal responsibilities while promoting taskwork and teamwork behaviours will assist in the integration of the individual contributions to the collective outcome.

Empowerment climate also positively related not only directly to both task and contextual performance behaviours but partially through both individual and team empowerment. Regarding the direct relationships, the unique variance empowerment climate explained in contextual behaviours $(61 \%)$ was nearly twice that explained in task behaviours $(36 \%)$. Empowerment climate also explained more variance in contextual behaviours than did both individual (42\%) and team (48\%) empowerment. This is an interesting finding especially in project context, as it suggests that empowerment climate is a much more influential factor in engendering behaviours that contribute to the maintenance of the psychological and social context of the work environment. Because of the high interdependence and interaction in project teams, this has implications for building cohesive teams which are necessary for collective task accomplishment.

While individual and team empowerment both explained almost equal variance in task behaviours (average 45\%), team empowerment was a stronger predictor of contextual behaviours. This is also an important finding as it suggest that while 
individual empowerment may contribute to high performance of one's tasks, his or her propensity to exhibit extra-role behaviours may depend on how empowered other team members are and able to reciprocate such behaviours towards their collective task accomplishment. Regarding the mediating role of psychological empowerment, both individual and team empowerment emerged as stronger mediators of the empowerment climate-task behaviours relationship than the empowerment climatecontextual behaviours relationship. This is not surprising, considering the much stronger direct relationship between empowerment climate and the contextual behaviours compared to the relationship with task behaviours. To engender extrarole behaviours, creating a more empowering work climate may therefore be more rewarding, while enhancing both an empowering work climate and fostering psychological empowerment at the same time may lead to higher in-role performance behaviours.

Taken together, these findings mirror in many ways the findings of Seibert et al (2004) and more recently Chen et al (2007), although the later were both in Western context. The replication of these results with a sample of predominantly Chinese (87\%) management staff is instructive. Positive performance effects from empowerment will seem contra-indicated in a cultural context that emphasizes social hierarchy, order and certainty. The consistency of the findings suggests that despite cultural differences, empowerment appear to be effective in engendering positive performance behaviours across cultures. Similar findings of positive outcomes within Chinese context have also been reported recently by Aryee and Chen (2006) and Liu et al (2007) as well as Humborstad et al (2008). Hui et al (2004) however found in a cross-cultural study that empowerment had a stronger effect on job satisfaction in low power-distance cultures than in high power-distance cultures. 
As expected, the positive impact of empowerment climate on taskwork and teamwork behaviours mirrored that on task and contextual behaviours discussed above. Like the case of task performance behaviours, empowerment climate explained less variance in taskwork behaviours (37\%) than did team empowerment (61\%). However, team empowerment explained more variance in teamwork behaviours (42\%) than did empowerment climate (32\%). In terms of individual and team performance therefore, team empowerment and empowerment climate play complimentarycomplementary roles, especially with regards to engendering extrarole behaviours. In the case of mediation, team empowerment more strongly mediated the relationship between empowerment climate and taskwork behaviours $(\Delta B=.57)$ than between empowerment climate and teamwork behaviours $(\Delta B=$ .35), mirroring the individual-level mediating results. Taken together, the results of the individual and team-level performance consequences of empowerment suggest that empowerment climate and psychological empowerment are not mutually exclusive but need to be simultaneously fostered to engender the needed job performance benefits of empowerment.

Notwithstanding the finding that high levels of team empowerment related positively to high individual performance, we found no support for our expectation that high team empowerment compensates for low levels of individual empowerment. Thus, there does not seem to be any inherent trade-off between empowering individuals and teams, resonating a similar finding recently by Chen et al (2007). This implies also that the achievement of performance improvement through empowerment efforts is contingent on the simultaneously empowerment of all team members to undertake their respective and eomplimentarycomplementary roles. 
Lastly, the analyses also show that the influence of the control variables on empowerment and performance behaviours in this study is marginal, explaining on the average less than $10 \%$ of variance in the case of empowerment and on average only $5 \%$ of variance in the performance behaviours. While there are significant associations between some control variables and both empowerment and performance behaviours in several of the models estimated, almost all such associations are spurious as explained in the analyses section. The significant finding involving control variables however is that the levels of team empowerment, individual performance behaviours (i.e. task and contextual) and team performance behaviours (i.e. taskwork and teamwork) reported are affected by the respondent's propensity to portray themselves and their teams in a favourable manner (i.e. social desirability), a justification for the decision to partial out such effects. The lack of significant findings between the demographic variables and performance behaviours is however consistent with similar findings in other studies on in-role and extra-role behaviours (c.f. Anvuur, 2008; Lam et al, 2002). Given the strong theoretical support for significant associations between some of the control variables and both empowerment and performance behaviours, the findings here ought to be interpreted with caution pending further confirmation in future research on the role of demographic variables on both empowerment and performance behaviours.

\section{Theoretical Implications}

Taken together, these findings have a number of theoretical implications. First, they add to our understanding of the important determinants of in-role and extra-role performance behaviours in construction project settings. This is an important finding in view of recent studies that have also shown that task related and context related behaviours are in turn, key determinants of project success (Ahadzie et al., 2008, 
Anvuur, 2008, Phua, 2004). Second, the study also helps advance empowerment theory regarding its generalizability across levels of analysis by adding to the growing body of empirical evidence (e.g. Chen et al., 2007, Kirkman and Rosen, 1999, Seibert et al., 2004). In this regard, our findings show that psychological empowerment positively relates to performance behaviours and also helps explain relationships between empowering work climate and performance behaviours simultaneously at both the individual- and team-level. Third, the positive effects of empowerment climate and psychological empowerment on performance behaviours in a mainly Chinese sample adds to the growing body of evidence regarding convergence in management practices across cultures as well as different work settings (c.f. Bakalis et al., 2007, Scott et al., 2003). Extending previous work in permanent organizational settings, our findings indicate that empowerment also has positive performance consequences in transient project settings.

\section{Practical/Managerial Implications}

Our findings also have several important implications for leading and managing project teams. The findings are particularly important for project leaders whose role often requires them to lead and motivate not only individuals but teams as a whole. For example, the finding that individual and team empowerment explained equal variance in task behaviours while team empowerment explained more variance in contextual behaviours, speaks directly to the importance of collective empowerment in engendering contextual behaviours in project teams. Managers seeking to engender contextual behaviours, such as cooperative acts which are particularly needed in the high interdependence context of projects, can therefore not selectively empower individuals, but must ensure that all team members are empowered if full benefits are to accrue from empowerment. 
In terms of organizational context our findings show that an empowering work climate enhances feelings of empowerment in both individuals and teams. Given that empowerment climate relates directly to organizational policies and practices, this presents managers with concrete organizational variables that can be manipulated to engender individual and team empowerment. In this regard, our findings point to organizational practices such as the provision of access to information, support, resources, opportunity to learn and grow as well as access to formal and informal sources of power as targets of manipulation by organizations and leaders desirous of empowering individuals and teams.

The evidence of convergence in management practices across cultures and contexts is also instructive for organizations, managers and academics worldwide who increasingly deal with multicultural project teams. In particular, as - Chinese companies increasingly make inroads into markets in Africa and the West, and companies from Western markets also expand into China, knowledge of what management practices are workable in a Chinese work context is imperative.

\section{Limitations and Future Research}

The study also has several limitations. First, its cross-sectional nature precludes inferring causality. Consequently, we were also unable to fully explore the reciprocal determinism among the environment, cognitive state and behaviour inherent in SCT that we drew on. For example, it is possible that improvement in individual and team performance leads managers to create an even more empowering work climate in which individuals subsequently feel more empowered. Second, the small sample size for the client and dual sub-samples at the individual-level and the small sub-sample sizes at the team-level, precluded any meaningful exploration of the relationships in the separate sub-samples at both levels for any subtle differences, especially that 
team (organization) type dummy variables were consistently significant in most of the models. Lastly, the study focussed on project management-level staff due to their strategic role in the project delivery process. It will however be interesting to examine these relationships among front-line staff. Given their lower formal power at the project level, psychological empowerment may even be a more important driver of performance for them.

The study also highlights avenues for further research. For example, future studies employing longitudinal research designs are required to validate the findings regarding the causal directions among empowerment climate, individual and team empowerment and performance behaviours. As the study did not also address how the elements of empowerment climate can be engendered, a clear line of enquiry is to unravel the organization and project-level factors conducive to the creation of an empowering work climate and hence the psychological empowerment of project participants. Also, the decomposition of the variance in individual empowerment earlier, showed that more that $80 \%$ of the variance manifest within-group, which can mainly be explained by individual-level variables. Thus, identifying individual-level factors that foster individual psychological empowerment may also be a worthwhile pursuit.

Finally, this paper went beyond the unitary focus of most research in the construction management domain to develop and empirically test an integrative multilevel model linking facets of empowerment and performance behaviours at the individual- and team-level. We hope that this encourages other researchers to adopt multilevel perspectives to the examination of issues related especially, to behaviour within construction management research. The paper also presents one of the first attempts 
to empirically examine the job performance implications of empowerment in the project context, evidence of which up until now, remained anecdotal.

\section{REFERENCES}

AHADZIE, D. K., PROVERBS, D. G. \& OLOMOLAIYE, P. (2008) Towards developing competency-based measures for construction project managers: Should contextual behaviours be distinguished from task behaviours? International Journal of Project Management, 26 (6), 631-645.

ANDERSON, N. R. \& WEST, M. A. (1998) Measuring climate for work group innovation: development and validation of the team climate inventory. Journal of Organizational Behaviour, 19 (3), 235-258.

ANVUUR, A. M. (2008) Cooperation in construction projects: Concept, antecedents and strategies, $\mathrm{PhD}$ Thesis, Department of Civil Engineering, The University of Hong Kong, Hong Kong.

ARMSTRONG, J. S. \& OVERTON, T. S. (1977) Estimating non-response bias in mail surveys. Journal of Marketing Research, 14 (3), 396-402.

ARYEE, S. \& CHEN, Z. X. (2006) Leader-member exchange in a Chinese context: Antecedents, the mediating role of psychological empowerment and outcomes. Journal of Business Research, 59 (7), 793-801.

BAKALIS, S., JOINER, T. A. \& ZIE, Z. (2007) Decision-making delegation: implications for Chinese managers' performance and satisfaction. International Journal of Human Resources Development and Management, 7 (3/4), 286 - 299.

BANDURA, A. (1977) Social learning theory, Prentice-Hall, Englewood Cliffs, N.J. BANDURA, A. (1986) Social foundations of thought and action: A social cognitive theory, Prentice-Hall, Englewood Cliffs, N.J.

BANDURA, A. (1997) Self-efficacy: The exercise of control, W.H. Freeman, New York.

BARON, R. M. \& KENNY, D. A. (1986) The moderator-mediator variable distinction in social psychological research: Conceptual, strategic, and statistical considerations. Journal of Personality and Social Psychology, 51 (6), 1173-1182. 
BICKEL, R. (2007) Multilevel analysis for applied research: It's just regression!, Guilford Press, New York.

BLANCHARD, K., CARLOS, J. P. \& RANDOLPH, A. (1999) The 3 keys to empowerment : release the power within people for astonishing results, 1st Edn. Berrett-Koehler Publishers, San Fransico.

BLIESE, P. D. \& HANGES, P. J. (2004) Being both too liberal and too conservative: The perils of treating grouped data as though they were independent. Organizational Research Methods, 7 (4), 400-417.

BORMAN, W. C. \& MOTOWIDLO, S. J. (1993) Expanding the criterion domain to include elements of contextual performance. IN SCHMITT, N., BORMAN, W. C. \& ASSOCIATES (Eds.) Personnel selection in organizations. JosseyBass, San Francisco, pp. 71-98.

BREAUGH, J. A. (2008) Important considerations in using statistical procedures to control for nuisance variables in non-experimental studies. Human Resource Management Review, 18 (4) 282-293.

BURKE, C. S., STAGL, K. C., KLEIN, C., GOODWIN, G. F., SALAS, E. \& HALPIN, S. M. (2006) What type of leadership behaviours are functional in teams? A meta-analysis. The Leadership Quarterly, 17 (3), 288-307.

BURKE, M. J., FINKELSTEIN, L. M. \& DUSIG, M. S. (1999) On average deviation indices for estimating interrater agreement. Organizational Research Methods, 2 (1), 49-68.

CAMPBELL, J. P., MCCLOY, R. A., OPPLER, S. H. \& SAGER, C. E. (1993) A theory of performance. IN SCHMITT, N., BORMAN, W. C. \& ASSOCIATES (Eds.) Personnel selection in organizations. Jossey-Bass, San Francisco, pp. 35-70.

CAMPION, M. A., PAPPER, E. M. \& MEDSKER, G. J. (1996) Relations between work team characteristics and effectiveness: A replication and extension. Personnel Psychology, 49 (2), 429.

CHEN, G. \& KANFER, R. (2006) Toward a systems theory of motivated behaviour in work teams research in organizational behaviour. IN STAW, B. M. (Ed.) Research in Organizational Behaviour. JAI, pp. 223-267.

CHEN, G., KIRKMAN, B. L., KANFER, R., ALLEN, D. \& ROSEN, B. (2007) A multilevel study of leadership, empowerment and performance in teams. Journal of Applied Psychology, 92 (2), 331-346. 
COHEN, J. \& COHEN, P. (1983) Applied multiple regression/correlation analysis for the behavioral sciences, Edn. Lawrence Erlbaum Associates, Hillsdale, N.J.

CONGER, J. A. \& KANUNGO, R. N. (1988) The empowerment process: Integrating theory and practice. Academy of Management Review, 13 (3), 471-482.

COOKE, W. N. (1994) Employee participation programs, group-based incentives, and company performance: A union-nonunion comparison. Industrial and Labour Relations Review, 47 (4), 594-609.

COURTNEY, R. \& WINCH, G. (2003) Re-engineering construction: the role of research and implementation Building Research \& Information, 31 (2), 172 178.

COURVILLE, T. \& THOMPSON, B. (2001) Use of structure coefficients in published multiple regression articles: $\beta$ is not enough. Educational and Psychological Measurement, 61 (2), 229-248.COX, R. F., ISSA, R. R. A. \& KOBLEGARD, K. (2005) Management's perception of key behavioural indicators for construction. Journal of Construction Engineering and Management, 131 (3), 368-376.

CRAMER, D. (2003) A cautionary tale of two statistics: Partial correlation and standardized partial regression. The Journal of Psychology, 137 (5), 507-511. CROWNE, D. P. \& MARLOWE, D. (1960) A new scale of social desirability independent of psychopathology. Journal of Consulting Psychology, 24 (4), 349-354.

DAINTY, A. R. J., BRYMAN, A. \& PRICE, A. D. F. (2002) Empowerment within the UK construction sector. Leadership and Organization Development Journal, 23 (5/6), 333-342.

DAINTY, A. R. J., BRYMAN, A., PRICE, A. D. F., GREASLEY, K., SOETANTO, R. \& KING, N. (2005) Project affinity: the role of emotional attachment in construction projects. Construction Management \& Economics, 23 (3), 241244.

DAINTY, A. R. J., CHENG, M.-I. \& MOORE, D. R. (2003) Redefining performance measures for construction project managers: An empirical evaluation. Construction Management and Economics, 21 (2), 209-218. 
DENISI, A. S. (2000) Performance appraisal and performance management: A multilevel analysis. IN KLEIN, K. J. \& KOZLOWSKI, S. W. J. (Eds.) Multilevel theory, research and methods in organizations: Foundations, extensions and new directions. Jossey-Bass, San Francisco, pp. 121-156.

DEWETTINCK, K., SINGH, J. \& BUYENS, D. (2003) Psychological empowerment in the workplace: Reviewing the empowerment effects on critical work outcomes. Vlerick Leuven Gent Working Paper Series. Ghent University.

DIMITRIADES, Z. \& KUFIDU, S. (2004) Individual, job, organizational and contextual correlates of employment empowerment: Some Greek evidence. Electronic Journal of Business Ethics and Organization Studies, 9 (2), 36-43.

EYLON, D. \& BAMBERGER, P. (2000) Empowerment cognitions and empowerment acts: Recognising the importance of gender. Group \& Organization Management, 25 (4), 354-372.

FIELD, A. P. (2005) Discovering statistics using SPSS : (and sex, drugs and rock'n'roll), 2nd Edn. SAGE, London.

FORRESTER, R. (2000) Empowerment: Rejuvenating a potent idea. Academy of Management Executive, 14 (3), 67-80.

GIST, M. E. \& MITCHELL, T. R. (1992) Self-Efficacy: A theoretical analysis of its determinants and malleability. Academy of Management Review, 17 (2), 183 211.

HACKMAN, J. R. (1987) The design of work teams. IN LORSCH, J. W. (Ed.) Handbook of organizational behaviour. Prentice Hall, Englewood Cliffs, N.J., pp. 315-342.

HACKMAN, J. R. \& OLDHAM, G. R. (1976) Motivation through the design of work: Test of a theory. Organizational behaviour and human performance, 16 (2), 250-279.

HAIR, J. F., ANDERSON, R. E., TATHAM, R. L. \& BLACK, W. C. (1998) Multivariate data analysis, 4th Edn. Prentice Hall, Upper Saddle River, N.J. HARDY, C. \& LEIBA-O'SULLIVAN, S. (1998) The power behind empowerment: Implications for research and practice. Human Relations, 51 (4), 451.

HOFMANN, D. A. (1997) An overview of the logic and rationale of hierarchical linear models. Journal of Management, 23 (6), 723-744. 
HUI, M. K., AU, K. \& FOCK, H. (2004) Empowerment effects across cultures. Journal of International Business Studies, 35 (1), 46-60.

HUMBORSTAD, S. I. W., HUMBORSTAD, B., WHITFIELD, R. \& PERRY, C. (2008) Implementation of empowerment in Chinese high power-distance organizations. The International Journal of Human Resource Management, 19 (7), 1349-1364.

JAMES, L. R., DEMAREE, R. G. \& WOLF, G. (1984) Estimating within-group inter-rater reliability with and without bias. Journal of Applied Psychology, 69 (1), 85-98.

KANTER, R. M. (1977) Men and women of the corporation, 1st Edn. Basic Books, New York.

KANTER, R. M. (1988) Empowering people to act on ideas. Executive Excellence, 5 (2), 5-6.

KANTER, R. M. (1993) Men and women of the corporation, 2nd Edn. Basic Books, New York.

KENNY, D. A. \& JUDD, C. M. (1986) Consequences of violating the independence assumption in analysis of variance. Psychological Bulletin, 99 (3), 422-431.

KENNY, D. A. \& JUDD, C. M. (1996) A general procedure for the estimation of interdependence. Psychological Bulletin, 119 (1), 138-148.

KIRKMAN, B. L. \& ROSEN, B. (1997) A model of work team empowerment. IN PASMORE, W. A. \& WOODMAN, R. W. (Eds.) Research in organizational change and development. JAI Press, England, pp. 131-167.

KIRKMAN, B. L. \& ROSEN, B. (1999) Beyond self-management: Antecedents and consequences of team empowerment. Academy of Management Journal, 42 (1), 58-74.

KIRKMAN, B. L., ROSEN, B., TESLUK, T. \& GIBSON, C. (2004) The impact of team empowerment on virtual team performance: The moderating role of face-to-face interaction. Academy of Management Journal, 47 (2), 175-192.

KLEIN, K. J. \& KOZLOWSKI, S. W. J. (2000) Multilevel theory, research, and methods in organizations: foundations, extensions, and new directions, $1 \mathrm{st}$ Edn. Jossey-Bass, San Francisco, California.

KOZLOWSKI, S. W. J. \& BELL, B. S. (2003) Work groups and teams in organizations. IN BORMAN, W. C., ILGEN, D. R. \& KLIMOSKI, R. J. 
(Eds.) Handbook of psychology: Industrial and organizational psychology.

Wiley, New Jersey, pp. 333-375.

LAM, S. S. K., CHEN, X.-P. \& SCHAUBROECK, H. (2002a) Participative decision making and employee performance in different cultures: The moderating effects of allocentrism/idiocenrism and efficacy. Academy of Management Journal, 45 (5), 905-914.LASCHINGER, S. H. K. (1996) A theoretical approach to studying work empowerment in nursing: a review of studies testing Kanter's theory of structural power in organizations. Nursing Administration Quarterly, 20 (2), 25-41.

LASCHINGER, S. H. K., FINEGAN, J., SHAMIAN, J. \& WILK, P. (2001) Impact of structural and psychological empowerment on job strain in nursing work settings: expanding Kanter's model. Journal of Nursing Administration, 31 (5), 260-272.

LEPINE, J. A., HANSON, M. A., BORMAN, W. C. \& MOTOWIDLO, S. J. (2000) Contextual performance and teamwork: Implications for staffing. IN FERRIS, G. R. \& ROWLAND, K. M. (Eds.) Research in personnel and human resources management. JAI Press Greenwich, pp. 53-90.

LIDEN, R. C. \& ARAD, S. (1996) A power perspective of empowerment and work groups: Implications for human resources management research. IN FERRIS, G. R. (Ed.) Research in personnel and human resources management. JAI Press, London, pp. 205-251.

LIDEN, R. C., WAYNE, S. J. \& SPARROWE, R. T. (2000) An examination of the mediating role of psychological empowerment on the relations between the job, interpersonal relationships, and work outcomes. Journal of Applied Psychology, 85 (3), 407-416.

LITWIN, G. H. \& STRINGER, R. A. (1968) Motivation and organizational climate, Division of Research, Graduate School of Business Administration, Harvard University, Boston.

LIU, A. M. M., CHIU, W. M. \& FELLOWS, R. (2007) Enhancing commitment through work empowerment. Engineering, Construction and Architectural Management, 14 (6), 568-580.

LIU, A. M. M. \& FANG, Z. (2006) A power-based leadership approach to project management. Construction Management \& Economics, 24 (5), 497-507. 
LOOSEMORE, M., DAINTY, A. R. J. \& LINGARD, H. (2003) Human resource management in construction projects: strategic and operational approaches, Spon, London.

LUKE, D. A. (2004) Multilevel modelling, Edn. Sage, California,Thousand Oaks.

MAASSEN, G. H. \& BAKKER, A. B. (2001) Suppressor variables in path models: Definitions and interpretations. Sociological Methods Research, 30 (2), 241270.

MACKINNON, D. P., LOCKWOOD, C. M., HOFFMAN, J. M., WEST, S. G. \& SHEETS, V. (2002) A comparison of methods to test mediation and other intervening variable effects. Psychological Methods, 7 (1), 83-104.

MARKS, M. A., MATHIEU, J. E. \& ZACCARO, S. J. (2001) A temporally based framework and taxonomy of team processes. Academy of Management Review, 26 (3), 356-376.

MATHIEU, J. E., GILSON, L. L. \& RUDDY, T. R. (2006) Empowerment and team effectiveness: An empirical test of an integrated model. Journal of Applied Psychology, 91 (1), 97-108.

MCINTYRE, R. M. \& SALAS, E. (1995) Measuring and managing for team performance: Emerging principles from complex environments. IN GUZZO, R. A., SALAS, E. \& ASSOCIATES (Eds.) Team effectiveness and decision making in organizations. Jossey-Bass, San Francisco, pp. 9-45.

MENON, S. (2001) Employee empowerment: An integrative psychological approach. Applied Psychology, 50 (1), 153-180.

MILLS, P. K. \& UNGSON, G. R. (2003) Reassessing the limits of structural empowerment: Organizational constitution and trust as controls. Academy of Management Review, 28 (1), 143-153.

MITCHELL, M. \& JOLLEY, J. (2001) Research design explained, 4th Edn. Harcourt College Publishers, Fort Worth, TX.

MOTOWIDLO, S. J. (2003) Job performance. IN BORMAN, W. C., ILGEN, D. R. \& KLIMOSKI, R. J. (Eds.) Handbook of psychology: Industrial and organizational psychology. John Wiley, Hoboken, New Jersey, pp. 39-53.

PARKER, S. K. \& TURNER, N. (2002) Work design and individual work performance: Research findings and an agenda for future inquiry. IN SONNENTAG, S. (Ed.) Psychological management of individual performance. John Wiley, Chichester, pp. 69-93. 
PETERS, L. H. \& O'CONNOR, E. J. (1980) Situational constraints and work outcomes: The influences of a frequently overlooked construct. Academy of Management Review, 5 (3), 391-397.

PHUA, F. (2004) Improving construction cooperation : New theoretical insights into how and why, Research Studies Press, Baldock, Hertfordshire.

PREACHER, K. J. \& LEONARDELLI, G. J. (2001) An interactive calculation tool for mediation tests, Available at http://www.people.ku.edu/ preacher/sobel/sobel.htm, accessed 15th July 2008.

RAUDENBUSH, S. W. \& BRYK, A. S. (2002) Hierarchical linear models :

Applications and data analysis methods, 2nd Edn. Sage Publications, Thousand Oaks, California.

REICHERS, A. E. \& SCHNEIDER, B. (1990) Climate and culture: An evolution of constructs. IN SCHNEIDER, B. (Ed.) Organizational climate and culture. Jossey-Bass, San Francisco, pp. 5-39.

ROUSSEAU, D. M. (1977) Technological differences in job characteristics, employee satisfaction and motivation: A synthesis of job design research and socio-technical systems theory. Organizational behaviour and human performance, 19 (1), 18-42.

SCOTT, D., BISHOP, J. \& CHEN, X. (2003) An examination of the relationship of employee involvement with job satisfaction, employee cooperation and intention to quit in U.S. invested enterprises in China. International Journal of Organizational Analysis, 1 (11), 3-20.

SEIBERT, S. E., SILVER, S. R. \& RANDOLPH, W. A. (2004) Taking empowerment to the next level: A multiple-level model of empowerment, performance, and satisfaction. Academy of Management Journal, 47 (3), 332349.

SHEA, G. P. \& GUZZO, R. A. (1987) Groups as human resources. IN ROWLAND, K. M. \& FERRIS, G. R. (Eds.) Research in personnel and human resources management. JAI Press, Greenwich, pp. 323-356.

SIEGALL, M. \& GARDNER, S. (2000) Contextual factors of psychological empowerment. Personnel Review, 29 (6), 703-722. 
SLEVIN, D. P. \& PINTO, J. K. (2004) An overview of behavioural issues in project management. IN MORRIS, P. W. G. \& PINTO, J. K. (Eds.) The Wiley guide to managing projects. John Wiley \& Sons, Hoboken, NJ, pp. 67-85.

SOBEL, M. E. (1982) Asymptotic confidence intervals for indirect effects in structural equation models. IN LEINHARDT, S. (Ed.) Sociological Methodology. American Sociological Association, Washington DC, pp. 290312.

SONNENTAG, S. \& FRESE, M. (2002) Performance concepts and performance theory. IN SONNENTAG, S. (Ed.) Psychological management of individual performance. John Wiley, Chichester, pp. 3-25.

SPREITZER, G. M. (1995a) Psychological empowerment in the workplace:

Dimensions, measurement and validation. Academy of Management Journal, 38 (5), 1442-1465.

SPREITZER, G. M. (1995b) An empirical test of a comprehensive model of intrapersonal empowerment in the workplace. American Journal of Community Psychology, 23 (5), 601-629.

SPREITZER, G. M. (1996) Social structural characteristics of psychological empowerment. Academy of Management Journal, 39 (2), 483-504.

SPREITZER, G. M. (1997) Toward a common ground in defining empowerment. IN PASMORE, W. A. \& WOODMAN, R. W. (Eds.) Research in organizational change and development. JAI Press, England, pp. 31-62.

SPREITZER, G. M. \& DONESON, D. (2008) Musings on the past and future of employee empowerment. IN CUMMINGS, T. (Ed.) Handbook of Organization Development. SAGE Publications, Los Angeles, pp. 311-324.

SPREITZER, G. M., KIZILOS, M. A. \& NASON, S. W. (1997) A dimensional analysis of the relationship between psychological empowerment and effectiveness, satisfaction, and strain. Journal of Management, 23 (5), 679704.

STEWART, G. L. \& BARRICK, M. R. (2000) Team structure and performance: Assessing the mediating role of intra-team process and the moderating role of task type. Academy of Management Journal, 43 (2), 135-148.

STRAHAN, R. \& GERBESI, K. C. (1972) Short, homogeneous versions of the Marlow-Crowne social desirability scale. Journal of Clinical Psychology, 28 (2), 191-193. 
TABACHNICK, B. G. \& FIDELL, L. S. (2001) Using multivariate statistics, Edn. Allyn and Bacon, Boston.

THAMHAIN, H. J. (2004) Linkages of project environment to performance: Lessons for team leadership. International Journal of Project Management, 22 (7), 533-544.

THOMAS, K. W. \& VELTHOUSE, B. A. (1990) Cognitive elements of empowerment: An interpretive model of intrinsic task motivation. Academy of Management Journal, 15 (4), 666-681.

TRIST, E. L., HIGGIN, G. W., MURRAY, H. \& POLLOCK, S. B. (1963) Organizational choice, Edn. Tavistock Institute, London.

TUULI, M. M. \& ROWLINSON, S. (2007a) Empowering project teams: Toward an integrative conceptualization of empowerment. IN AHMED, S. M., AZHAR, S. \& MOHAMED, S. (Eds.) Proceedings of the 4th International Conference on Construction in the 21st Century (CITC IV). Gold Coast, Australia, pp. 240-247.

TUULI, M. M. \& ROWLINSON, S. (2007b) Towards a conceptual framework of empowerment and job performance in project teams. IN BOYD, D. (Ed.) Proceedings of the 23rd ARCOM Annual Conference 2007. Belfast, Northern Ireland, Association of Researchers in Construction Management, pp. 3-12.

UHL-BIEN, M. \& GRAEN, G. B. (1998) Individual self-management: Analysis of professionals' self-managing activities in functional and cross-functional work teams. Academy of Management Journal, 41 (3), 340.

VAN SCOTTER, J. R. \& MOTOWIDLO, S. J. (1996) Interpersonal facilitation and job dedication as separate facets of contextual performance. Journal of Applied Psychology, 81 (5), 525-531.

WALL, T. D., CORDERY, J. L. \& CLEGG, C. W. (2002) Empowerment, performance, and operational uncertainty: A theoretical integration. Applied Psychology, 51 (1), 146-169.

WALL, T. D., WOOD, S. J. \& LEACH, D. J. (2004) Empowerment and performance. IN COOPER, C. L. \& ROBERTSON, I. T. (Eds.) International review of industrial and organizational psychology. John Wiley, Chichester, pp. 1-46. 
WILLIAMS, L. J. \& ANDERSON, S. E. (1991) Job satisfaction and organizational commitment as predictors of organizational citizenship and in-role behaviours. Journal of Management, 17 (3), 601-617. 

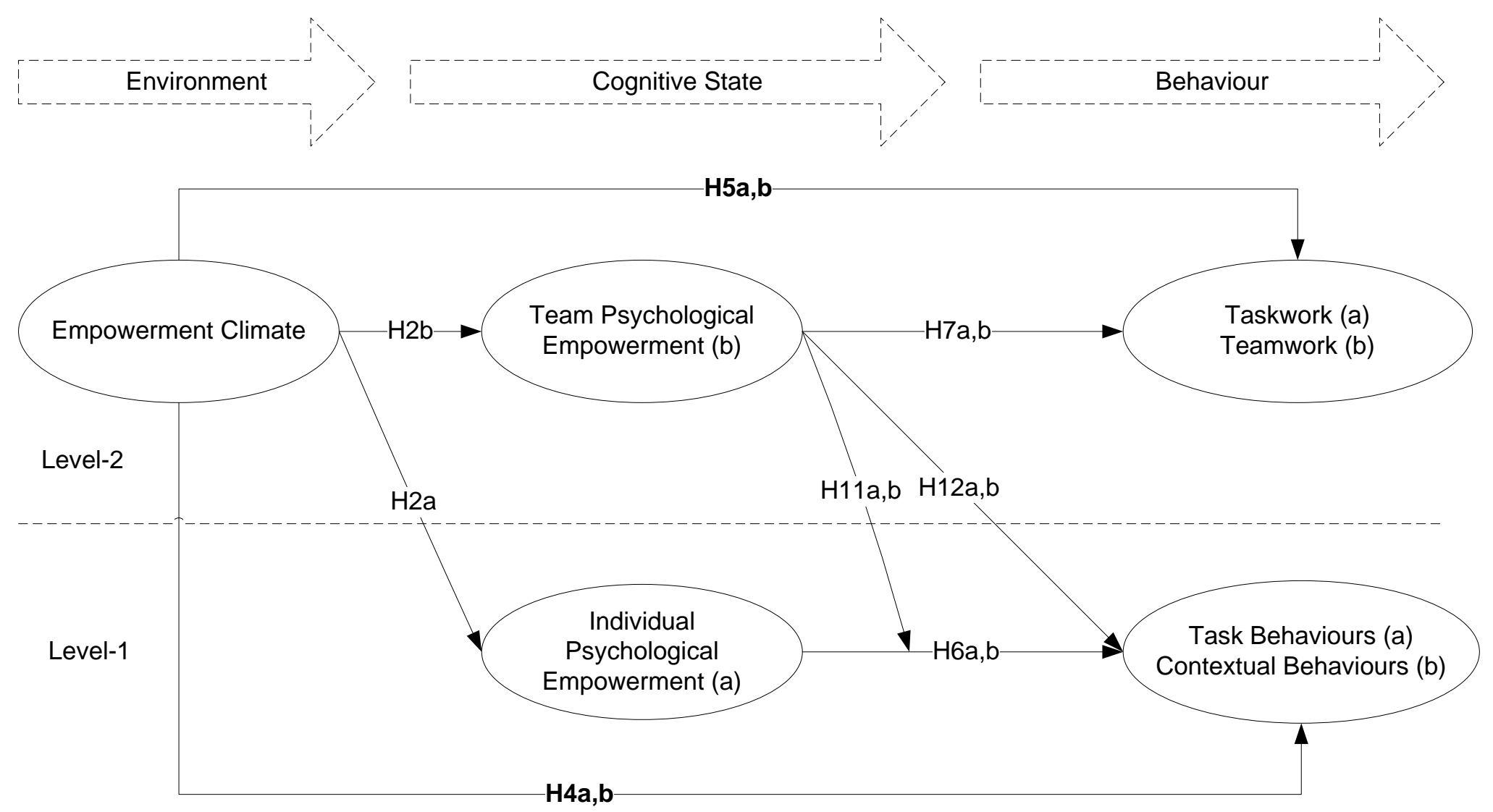

Figure 1: Integrative Multilevel Model of Empowerment and Job Performance 
Table 1 Descriptive Statistics and Correlations

\begin{tabular}{|c|c|c|c|c|c|c|c|c|c|c|c|c|c|c|c|c|c|c|c|c|c|c|c|c|c|c|}
\hline & Variables & Mean & SD & $r_{w g}$ & $\mathrm{AD}_{\mathrm{M}}$ & $\mathrm{AD}_{\mathrm{Md}}$ & 1 & 2 & 3 & 4 & 5 & 6 & 7 & 8 & 9 & 10 & 11 & 12 & 13 & 14 & 15 & 16 & 17 & 18 & 19 & 20 \\
\hline & Control Variables & & & & & & & & & & & & & & & & & & & & & & & & & \\
\hline 1 & Age & 0.53 & 0.50 & & & & - & & & & & & & & & & & & & & & & & & & \\
\hline 2 & Gender & 0.89 & 0.31 & & & & .09 & - & & & & & & & & & & & & & & & & & & \\
\hline 3 & Education & 0.43 & 0.50 & & & & $.21^{*}$ & -.08 & - & & & & & & & & & & & & & & & & & \\
\hline 4 & Nationality & 0.82 & 0.39 & & & & -.10 & .02 & -.09 & - & & & & & & & & & & & & & & & & \\
\hline 5 & Ethnicity & 0.87 & 0.34 & & & & $.11 \dagger$ & -.03 & -.03 & $.66^{*}$ & - & & & & & & & & & & & & & & & \\
\hline 6 & Firm Size & 0.77 & 0.42 & & & & .03 & .01 & -.02 & .07 & .03 & - & & & & & & & & & & & & & & \\
\hline 7 & Firm age & 35.49 & 18.88 & & & & .07 & .01 & .07 & -.08 & -.02 & $.19^{*}$ & - & & & & & & & & & & & & & \\
\hline 8 & Team Type 1 (Contractor) & 0.46 & 0.50 & & & & $-.16 \dagger$ & $.22^{*}$ & $-.25^{*}$ & .03 & -.05 & .02 & .03 & - & & & & & & & & & & & & \\
\hline 9 & Team Type 2 (Client) & 0.20 & 0.40 & & & & $.14 \dagger$ & -.01 & $.20^{*}$ & -.04 & -.03 & $.11^{\sim}$ & .06 & $-.46^{*}$ & - & & & & & & & & & & & \\
\hline 10 & Team Type 3 (Dual) & 0.10 & 0.30 & & & & .07 & -.02 & .07 & .09 & .08 & $.18^{*}$ & .08 & $-.31^{*}$ & $-.17^{*}$ & - & & & & & & & & & & \\
\hline 11 & Tenure (industry) & 16.89 & 8.46 & & & & $.79^{*}$ & .04 & $.18^{*}$ & $-.17 \dagger$ & .07 & -.01 & .09 & -.09 & .06 & .09 & - & & & & & & & & & \\
\hline \multirow[t]{2}{*}{12} & Number of Respondents & 4.00 & 2.00 & & & & .06 & -.07 & -.08 & .09 & .06 & $.23^{*}$ & $.15 \dagger$ & .02 & -.01 & $.10^{\circ}$ & .03 & & & & & & & & & \\
\hline & Performance Behaviours & & & & & & & & & & & & & & & & & & & & & & & & & \\
\hline 13 & Contextual Behaviours & 3.66 & 0.73 & & & & .12 & .10 & -.02 & .03 & -.03 & .04 & -.02 & $-.11^{\sim}$ & .05 & $.10^{-}$ & .09 & .07 & (.95) & & & & & & & \\
\hline 14 & Task Behaviours & 3.90 & 0.80 & & & & $.18^{*}$ & .12 & .04 & .00 & -.05 & .01 & .07 & $-.14 \dagger$ & .07 & .12 & $.17^{*}$ & .04 & $.67^{*}$ & (.94) & & & & & & \\
\hline 15 & Teamwork Behaviours $^{d}$ & 3.32 & 0.39 & $.95 \dagger$ & $.33 \dagger$ & $.28 \dagger$ & .07 & -.03 & -.01 & .03 & -.03 & -.01 & .03 & -.06 & -.06 & .07 & .07 & .07 & $.24 *$ & $.25^{*}$ & $(.96)$ & & & & & \\
\hline \multirow[t]{2}{*}{16} & Taskwork Behaviours $^{d}$ & 3.52 & 0.48 & $.92 \dagger$ & $.45 \dagger$ & $.37 \uparrow$ & $.15 \dagger$ & -.04 & .10 & -.02 & -.09 & -.04 & .07 & -.10 & .01 & $.20^{*}$ & $.16^{*}$ & $.15 \dagger$ & $.31^{*}$ & $.37^{*}$ & $.71^{*}$ & $(.92)$ & & & & \\
\hline & Empowerment & & & & & & & & & & & & & & & & & & & & & & & & & \\
\hline 17 & Individual Empowerment & 3.60 & 0.74 & & & & $.11^{\sim}$ & .08 & -.02 & -.08 & $-.11^{\sim}$ & $-.19^{*}$ & .00 & .04 & $-.14 \dagger$ & -.07 & $.15^{*}$ & .03 & $.67^{*}$ & $.69^{*}$ & $.22^{*}$ & $.29 *$ & $(.91-.82)$ & & & \\
\hline 18 & Team Empowerment ${ }^{\mathrm{d}}$ & 3.50 & 0.41 & $.96 \dagger$ & . $44 \dagger$ & $.36 \dagger$ & $.13 \dagger$ & -.06 & .02 & -.08 & .12 & -.07 & -.03 & -.09 & -.05 & .09 & .12 & -.06 & $.36^{*}$ & $.36^{*}$ & $.67^{*}$ & $.80^{*}$ & $.80^{*}$ & $(.95)$ & & \\
\hline \multirow[t]{2}{*}{19} & Empowerment Climate $^{d}$ & 3.39 & 0.40 & .84 & .50 & $.45^{*}$ & .05 & -.01 & -.04 & -.02 & .06 & -.06 & -.08 & $.11^{\sim}$ & -.04 & -.03 & .04 & -.06 & $.41^{*}$ & $.26^{*}$ & $.58^{*}$ & $.63^{*}$ & $.63^{*}$ & $.70^{*}$ & $(.92-.84)$ & \\
\hline & Social Desirability & & & & & & & & & & & & & & & & & & & & & & & & & \\
\hline 20 & Social Desirability & 5.95 & 1.56 & & & & $.17^{*}$ & -.10 & $.17^{*}$ & .07 & .03 & .07 & -.04 & $-.29 *$ & $.20^{*}$ & .04 & $.13 \dagger$ & .09 & $.20^{*}$ & $.19^{*}$ & .12 & $.24 *$ & .05 & $23^{*}$ & $.19 *$ & - \\
\hline
\end{tabular}

\section{NOTE: $\sim \mathrm{p}<0.05 ; \mathrm{p}<0.01 ;{ }^{*} \mathrm{p}<0.001$.}

andividual-level sample size $=380$ indivi
${ }^{\mathrm{b}}$ Chronbach's alphas are on the diagonal.

${ }^{\circ}$ Chronbach's alphas are on the diagonal.
${ }^{\circ}$ Control variables are coded as follows: Gender is coded $1=$ Male, $0=$ Female; Age is coded $1=$ Old (over 40 years old), $0=$ Young (under 40 years old); Education is coded $1=$ Graduate degree or higher, $0=$ Bachelors degree or lower; Nationality is coded $1=$ Hong Kong or China National, $0=$ Other; Ethnicity is coded $1=$ Chinese, $0=$ Other; Firm size is coded $1=$ Large (100 or more employees), $0=$ Small (less than 100 employees); Team Type 1 (CM) is coded $1=$ Contractor, $0=$ Others; Team Type 2 (Client) is coded $1=$ Client, $0=$ Others and Team Type 3 (Dual) is coded $1=$ Dual (Client + Consultant), $0=$ Others, thus, Consultant is the

reference in all cases
${ }^{d}$ The team mean values of these variables are used, thus, correlations and significant tests associated with these variables should be viewed with caution

'Correlations involving categorical variables are Spearman's rhos, all other correlations are Pearson's product-moment correlations.
fAll variables except the social desirability measure and categorical variables,_were scored on a 5-point Likert scale with higher scores indicating more of the construct. 
Table 2 HLM Analyses of Empowerment Climate as Predictor of Individual Empowerment (Hypotheses H2a)

\begin{tabular}{|c|c|c|c|}
\hline \multirow{4}{*}{ Variables } & \multicolumn{3}{|c|}{ Individual Empowerment } \\
\hline & \multicolumn{3}{|c|}{ Model } \\
\hline & $1 a$ & $1 b$ & $1 c$ \\
\hline & $B(S . E)$ & $B(S . E)$ & $B(S . E)$ \\
\hline Gender & & $-.26(.13)^{\sim}$ & $-.11(.08)$ \\
\hline Age & & $-.06(.13)$ & $.04(.09)$ \\
\hline Education & & $.08(.08)$ & $-.03(.06)$ \\
\hline Nationality & & $-.09(.14)$ & $-.01(.09)$ \\
\hline Ethnicity & & $-.28(.17)$ & $-.10(.11)$ \\
\hline Tenure (industry) & & $.01(.01)$ & $.01(.01)$ \\
\hline Firm Size & & $.28(.11) \dagger$ & $.29(.10) \dagger$ \\
\hline Firm Age & & $.00(.00)$ & $.00(.00)$ \\
\hline Team Type $1(\mathrm{CM})$ & & $.27(.16)$ & $.30(.16)$ \\
\hline Team Type 2 Client) & & $.11(.15)$ & $.10(.15)$ \\
\hline Team Type 3 (Dual) & & $-.09(.16)$ & $-.06(.16)$ \\
\hline No of Respondents & & $.03(.03)$ & $.04(.03)$ \\
\hline Social Desirability & & $.04(.03)$ & $.01(.02)$ \\
\hline Empowerment Climate & & - & $.77(.04)^{*}$ \\
\hline$\sigma^{2}$ & $.47(.04)^{*}$ & $.47(.04)^{*}$ & $.16(.02)^{*}$ \\
\hline$\tau_{00}$ & $.08(.03) \dagger$ & $.04(.03)$ & $.12(.03)^{*}$ \\
\hline$R_{1}^{2}$ & - & .07 & .49 \\
\hline$\Delta R_{1}^{2}$ (Unique) & - & .07 & .42 \\
\hline$\Delta$ Deviance (-2LL) & - & $69.69 *$ & $244.98^{*}$ \\
\hline
\end{tabular}


Table 3 OLS Regression Analysis of Empowerment Climate as Predictor of Team Empowerment (Hypotheses H2b)

\begin{tabular}{|c|c|c|}
\hline \multirow{4}{*}{ Variables } & \multicolumn{2}{|c|}{ Team Empowerment } \\
\hline & \multicolumn{2}{|c|}{ Model } \\
\hline & $2 a$ & $2 b$ \\
\hline & $B(S . E)$ & $B(S . E)$ \\
\hline Firm Size & $-.07(.10)$ & $-.01(.07)$ \\
\hline Firm Age & $.00(.00)$ & $.00(.00)$ \\
\hline Team Type $1(\mathrm{CM})$ & $-.01(.10)$ & $-.16(.08)^{\sim}$ \\
\hline Team Type 2 (Client) & $-.20(.12)$ & $-.19(.09)^{\sim}$ \\
\hline Team Type 3 (Dual) & $.04(.15)$ & $.03(.11)$ \\
\hline No of Respondents & $-.02(.03)$ & $-.01(.02)$ \\
\hline Social Desirability & $.09(.03) \dagger$ & $.03(.02)$ \\
\hline Empowerment Climate & - & $.70(.07) *$ \\
\hline$\overline{R^{2}}$ & .11 & .55 \\
\hline$\Delta R^{2}$ & .11 & .44 \\
\hline F Change & 1.80 & $98.96 *$ \\
\hline Durban-Watson test & & 15 \\
\hline$A N O V A(F)$ & 1.80 & $15.44 *$ \\
\hline Adjusted $R^{2}$ & .05 & .51 \\
\hline Unique Variance & .05 & .46 \\
\hline
\end{tabular}

NOTE: $\sim \mathrm{p}<0.05 ; \dagger \mathrm{p}<0.01 ;{ }^{*} \mathrm{p}<0.001$.

${ }^{\mathrm{a}}$ Team-level sample size $=115$ teams (380 individuals).

${ }^{\mathrm{b}}$ Unstandardized coefficients are reported

with standard errors in parenthesis. 
Table 4 HLM Analysis of Empowerment Climate as Predictor of Task and Contextual Behaviours (Hypotheses H4a,b; H6a,b; H12a,b)

\begin{tabular}{|c|c|c|c|c|c|c|c|c|c|c|}
\hline \multirow{4}{*}{ Variables } & \multicolumn{5}{|c|}{ Task Behaviours } & \multicolumn{5}{|c|}{ Contextual Behaviours } \\
\hline & \multicolumn{5}{|c|}{ Model } & \multicolumn{5}{|c|}{ Model } \\
\hline & $3 a$ & $3 b$ & $3 c$ & $3 d$ & $3 e$ & $4 a$ & $4 b$ & $4 c$ & $4 d$ & $4 e$ \\
\hline & & $B(S . E)$ & $B(S . E)$ & $B(S . E)$ & $B(S . E)$ & & $B(S . E)$ & $B(S . E)$ & $B(S . E)$ & $B(S . E)$ \\
\hline Gender & & $-.37(.14) \dagger$ & $-.18(.11)$ & $-.14(.09)$ & $-.12(.10)$ & & $-.34(.13) \dagger$ & $-.10(.07)$ & $-.11(.08)$ & $-.08(.08)$ \\
\hline Age & & $-.14(.15)$ & $-.03(.11)$ & $-.09(.10)$ & $-.04(.10)$ & & $-.13(.13)$ & $-.02(.07)$ & $-.09(.08)$ & $-.05(.08)$ \\
\hline Education & & $.06(.09)$ & $-.04(.07)$ & $.00(.06)$ & $.01(.06)$ & & $.12(.08)$ & $-.01(.05)$ & $.06(.05)$ & $.07(.05)$ \\
\hline Nationality & & $-.15(.16)$ & $-.04(.12)$ & $-.04(.10)$ & $-.06(.11)$ & & $-.07(.14)$ & $.05(.08)$ & $.04(.09)$ & $.02(.09)$ \\
\hline Ethnicity & & $-.20(.18)$ & $-.03(.14)$ & $-.05(.12)$ & $-.05(.13)$ & & $-.07(.17)$ & $-.06(.09)$ & $-.11(.11)$ & $-.02(.10)$ \\
\hline Tenure (industry) & & $.01(.01)$ & $.00(.01)$ & $-.00(.01)$ & $.00(.01)$ & & $.00(.01)$ & $-.00(.00)$ & $-.01(.00)$ & $-.00(.00)$ \\
\hline Firm Size & & $.05(.12)$ & $.04(.11)$ & $-.18(.10)$ & $.04(.10)$ & & $-.04(.12)$ & $-.04(.08)$ & $-.26(.10) \dagger$ & $-.05(.10)$ \\
\hline Firm Age & & $.00(.00)$ & $.00(.00)$ & $.00(.00)$ & $.00(.00)$ & & $-.00(.00)$ & $-.00(.00)$ & $-.00(.00)$ & $-.00(.00)$ \\
\hline Team Type 1 (CM) & & $-.20(.18)$ & $-.18(.17)$ & $-.42(.15) \dagger$ & $-.16(.15)$ & & $-.18(.18)$ & $-.17(.13)$ & $-.39(.16) \sim$ & $-.16(.15)$ \\
\hline Team Type 2 Client) & & $-.38(.17)^{\sim}$ & $-.40(.15) \dagger$ & $-.47(.14)^{*}$ & $-.23(.14)$ & & $-.31(.17)$ & $-.34(.12) \dagger$ & $-.40(.15) \dagger$ & $-.16(.14)$ \\
\hline Team Type 3 (Dual) & & $-.20(.18)$ & $-.19(.17)$ & $-.15(.15)$ & $-.03(.15)$ & & $-.16(.18)$ & $-.14(.13)$ & $-.09(.16)$ & $.02(.15)$ \\
\hline No respondents & & $.00(.03)$ & $.01(.03)$ & $-.03(.03)$ & $.01(.03)$ & & $.01(.03)$ & $.02(.03)$ & $-.01(.03)$ & $.02(.03)$ \\
\hline Social Desirability & & $.08(.03) \dagger$ & $.04(.02)$ & $.05(.02) \sim$ & $.03(.02)$ & & $.08(.03) \dagger$ & $.04(.02)^{\sim}$ & $.04(.02) \sim$ & $.03(.02)$ \\
\hline Individual Empowerment & & - & - & $81(.04)_{-}^{*}$ & - & & - & - & $.75(.04)^{*}$ & - \\
\hline Team Empowerment & & - & - & - & $.79(.04)^{*}$ & & - & - & - & $.76(.03)^{*}$ \\
\hline Empowerment Climate & & - & $.74(.05)^{*}$ & - & - & & - & $.83(.03)^{*}$ & - & - \\
\hline$\sigma^{2}$ & $.55(.05)^{*}$ & $.55(.05)^{*}$ & $.27(.03)^{*}$ & $.22(.02)^{*}$ & $.23(.02)^{*}$ & $.45(.04)^{*}$ & $.43(.04)^{*}$ & $.11(.01)^{*}$ & $.15(.01)^{*}$ & $.14(.01)^{*}$ \\
\hline$\tau_{00}$ & $.09(.03) \dagger$ & $.05(.04)$ & $.10(.03)^{*}$ & $.09(.02)^{*}$ & $.09(.02)^{*}$ & $.09(.03) \dagger$ & $.09(.04) \dagger$ & $.08(.02)^{*}$ & $.14(.03)^{*}$ & $.12(.02)^{*}$ \\
\hline$R !$ & - & .06 & .42 & .52 & .50 & - & .04 & .65 & .46 & .52 \\
\hline$\Delta R \boldsymbol{R}$ (Unique) & - & .06 & .36 & .46 & .44 & - & .04 & .61 & .42 & .48 \\
\hline$\Delta$ Deviance (-2LL) & - & $78.69 *$ & $175.11^{*}$ & $246.45^{*}$ & $227.68^{*}$ & - & $66.25^{*}$ & $365.34 *$ & $263.84 *$ & $285.20^{*}$ \\
\hline
\end{tabular}


Table 5 OLS Regression Analyses of the Direct and Mediated Effects of Empowerment Climate on Team Performance Behaviours (Hypotheses H5a,b; H7a,b; H10a,b)

\begin{tabular}{|c|c|c|c|c|c|c|c|c|}
\hline \multirow{4}{*}{ Variables } & \multicolumn{4}{|c|}{ Taskwork } & \multicolumn{4}{|c|}{ Teamwork } \\
\hline & \multicolumn{4}{|c|}{ Model } & \multicolumn{4}{|c|}{ Model } \\
\hline & $5 a$ & $5 b$ & $5 c$ & $5 d$ & $6 a$ & $6 b$ & $6 c$ & $6 d$ \\
\hline & $B(S . E)$ & $B(S . E)$ & $B(S . E)$ & $B(S . E)$ & $B(S . E)$ & $B(S . E)$ & $B(S . E)$ & $B(S . E)$ \\
\hline Firm Size & $-.17(.11)$ & $-.10(.08)$ & $-.10(.06)$ & $-.09(.06)$ & $.02(.10)$ & $.07(.08)$ & $.07(.07)$ & $.08(.07)$ \\
\hline Firm Age & $.00(.00)$ & $.00(.00)$ & $.00(.00)$ & $.00(.00)$ & $.00(.00)$ & $.00(.00)$ & $.00(.00)$ & $.00(.00)$ \\
\hline Team Type 1 (CM) & $.07(.12)$ & $-.08(.09)$ & $.08(.07)$ & $.05(.07)$ & $-.06(.11)$ & $-.19(.09)^{\sim}$ & $-.06(.08)$ & $-.11(.08)$ \\
\hline Team Type 2 Client) & $-.08(.14)$ & $-.06(.11)$ & $.11(.08)$ & $.09(.08)$ & $-.20(.13)$ & $-.19(.10)$ & $-.06(.09)$ & $-.09(.09)$ \\
\hline Team Type 3 (Dual) & $.30(.17)$ & $.28(.14)^{\sim}$ & $.26(.10) \dagger$ & $.26(.10) \dagger$ & $.01(.16)$ & $-.01(.13)$ & $-.02(.12)$ & $-.02(.11)$ \\
\hline No of Respondents & $.04(.04)$ & $.05(.03)$ & $.05(.02) \dagger$ & $.05(.02) \dagger$ & $.01(.03)$ & $.02(.03)$ & $.02(.02)$ & $.02(.02)$ \\
\hline Social Desirability & $.10(.04) \dagger$ & $.03(.03)$ & $.02(.02)$ & $.01(.02)$ & $.04(.03)$ & $-.02(.03)$ & $-.03(.02)$ & $-.03(.02)$ \\
\hline Team Empowerment & - & - & $.93(.07)^{*}$ & $.82(.09) *$ & - & - & $.69(.07)^{*}$ & $.50(.10)^{*}$ \\
\hline Empowerment Climate & - & $.72(.09) *$ & - & $.15(.09)$ & - & $.61(.08)^{*}$ & - & $.26(.10) \dagger$ \\
\hline$\Delta \boldsymbol{\beta} \boldsymbol{\nabla}$ & - & - & - & .57 & - & - & - & .35 \\
\hline$R^{2}$ & .14 & .49 & .71 & .72 & .04 & .39 & .48 & .51 \\
\hline$\Delta R^{2}$ & .14 & .35 & .57 & .01 & .04 & .35 & .44 & .03 \\
\hline F Change & $2.46^{\sim}$ & $70.32 *$ & $204.11 *$ & 2.69 & 0.66 & $58.73 *$ & $86.00 *$ & $6.65^{\sim}$ \\
\hline Durban-Watson test & & 1.98 & 1.90 & 1.90 & & 1.99 & 2.12 & 2.07 \\
\hline$A N O V A(F)$ & $2.46^{\sim}$ & $12.37^{*}$ & $31.86^{*}$ & $29.09 *$ & 0.66 & $8.24^{*}$ & $11.80^{*}$ & $11.80^{*}$ \\
\hline Adjusted $R^{2}$ & .08 & .45 & .69 & .70 & .02 & .34 & .44 & .47 \\
\hline Unique Variance & .08 & .37 & .61 & .62 & .02 & .32 & .42 & .45 \\
\hline
\end{tabular}

NOTE: $\sim \mathrm{p}<0.05 ; \uparrow \mathrm{p}<0.01 ;{ }^{*} \mathrm{p}<0.001$.

${ }^{\mathrm{a}}$ Team-level sample size $=115$ teams ( 380 individuals). 
${ }^{b}$ Unstandardized coefficients are reported with standard errors in parenthesis. 
Table 6 HLM Analyses of Mediated and Moderated Effects of Empowerment on Individual

Performance Behaviours (Hypotheses H8a,b; H9a,b; H11a,b)

\begin{tabular}{|c|c|c|c|c|c|c|}
\hline \multirow{4}{*}{ Variables } & \multicolumn{3}{|c|}{ Task Behaviours } & \multicolumn{3}{|c|}{ Contextual Behaviours } \\
\hline & \multicolumn{3}{|c|}{ Model } & \multicolumn{3}{|c|}{ Model } \\
\hline & $7 a$ & $7 b$ & $7 c$ & $8 a$ & $8 b$ & $8 c$ \\
\hline & $B(S . E)$ & $B(S . E)$ & $B(S . E)$ & $B(S . E)$ & $B(S . E)$ & $B(S . E)$ \\
\hline Gender & $-.12(.09)$ & $-.13(.10)$ & $-.10(.09)$ & $-.06(.07)$ & $-.07(.07)$ & $-.06(.07)$ \\
\hline Age & $-.06(.09)$ & $-.03(.10)$ & $-.06(.09)$ & $-.03(.07)$ & $-.03(.07)$ & $-.07(.07)$ \\
\hline Education & $-.02(.06)$ & $-.01(.06)$ & $-.00(.06)$ & $.00(.04)$ & $.01(.04)$ & $.06(.05)$ \\
\hline Nationality & $-.03(.10)$ & $-.05(.10)$ & $-.05(.10)$ & $.05(.07)$ & $.05(.07)$ & $.03(.08)$ \\
\hline Ethnicity & $-.04(.12)$ & $-.03(.13)$ & $-.02(.12)$ & $-.09(.08)$ & $-.05(.09)$ & $-.06(.10)$ \\
\hline Tenure (industry) & $-.00(.01)$ & $.00(.01)$ & $.00(.01)$ & $-.00(.00)$ & $-.00(.00)$ & $-.00(.00)$ \\
\hline Firm Size & $-.12(.09)$ & $.04(.10)$ & $-.10(.09)$ & $-.13(.08)$ & $-.04(.08)$ & $-.15(.09)$ \\
\hline Firm Age & $.00(.00)$ & $.00(.00)$ & $.00(.00)$ & $-.00(.00)$ & $-.00(.00)$ & $-.00(.00)$ \\
\hline Team Type 1 (CM) & $-.36(.15)^{\sim}$ & $-.17(.15)$ & $-.31(.14)^{\sim}$ & $-.26(.13)^{\sim}$ & $-.17(.13)$ & $-.26(.15)$ \\
\hline Team Type 2 Client) & $-.46(.13)^{*}$ & $-.28(.14)^{\sim}$ & $-.35(.13) \dagger$ & $-.37(.11) \dagger$ & $-.28(.12)^{\sim}$ & $-.26(.14)$ \\
\hline Team Type 3 (Dual) & $-.16(.14)$ & $-.07(.15)$ & $-.08(.14)$ & $-.12(.12)$ & $-.08(.13)$ & $-.01(.15)$ \\
\hline No of Respondents & $-.02(.03)$ & $.01(.03)$ & $-.01(.03)$ & $.01(.03)$ & $.02(.03)$ & $.00(.03)$ \\
\hline Social Desirability & $.04(.02)^{\sim}$ & $.03(.02)$ & $.03(.02)$ & $.04(.02)^{\sim}$ & $.04(.02)^{\sim}$ & $.03(.02)$ \\
\hline Individual Empowerment & $.60(.06)^{*}$ & - & - & $.29(.04)^{*}$ & - & - \\
\hline Team Empowerment & - & $.60(.07)^{*}$ & $.48(.06)^{*}$ & - & $.28(.05)^{*}$ & $.36(.05)^{*}$ \\
\hline Empowerment Climate & $.29(.06)^{*}$ & $.23(.07) \dagger$ & $.41(.06) *$ & $.61(.04) *$ & $.59(.05) *$ & $.47(.05) *$ \\
\hline Team Empower't X Indiv. Empower't & - & - & $-.02(.04)$ & - & - & $-.03(.04)$ \\
\hline$\Delta \beta \boldsymbol{\nabla}$ & .45 & .51 & - & .22 & .24 & - \\
\hline$\sigma^{2}$ & $.21(.02)^{*}$ & $.22(.02)^{*}$ & $.20(.02)^{*}$ & $.09(.01)^{*}$ & $.10(.01)^{*}$ & $.12(.01)^{*}$ \\
\hline$\tau_{00}$ & $.08(.02)^{*}$ & $.09(.02)^{*}$ & $.07(.02)^{*}$ & $.08(.02)^{*}$ & $.09(.02)^{*}$ & $.11(.01)^{*}$ \\
\hline$R_{1}^{q}$ & .55 & .52 & .58 & 69 & .65 & .57 \\
\hline$\Delta R_{1}^{2}$ (Unique-main effects) & .49 & .46 & .52 & .65 & .61 & .53 \\
\hline$\Delta R_{1}^{q}$ (Unique-Interaction) & .03 & .02 & - & .23 & .13 & - \\
\hline$\Delta$ Deviance $(-2 \mathrm{LL})$ & $261.70^{*}$ & $235.42 *$ & $274.07 *$ & $404.27 *$ & $213.78 *$ & $319.17 *$ \\
\hline
\end{tabular}

NOTE: $\mathrm{p}<0.05 ; \uparrow \mathrm{p}<0.01 ; * \mathrm{p}<0.001$

${ }^{a}$ Individual-level sample size $=380$ individuals (nested in 115 project teams).

${ }^{\mathrm{b}}$ Unstandardized coefficients are reported with standard errors in parenthesis.

${ }^{\mathrm{c}}$ This is the unique variance explained by Empowerment Climate over and above that explained by Psychological Empowerment. 
Table 7 Analyses of Indirect Effects of Empowerment Climate on Performance Behaviours

(Hypotheses H6c,d; 7c,d; 8e,f)

\begin{tabular}{clr}
\hline Hypothesis & Cross-Level Indirect Path & B' $(\mathbf{z})$ \\
\hline $\mathrm{H} 8 \mathrm{a}$ & Empower't Climate $\rightarrow$ Indiv. Empower't $\rightarrow$ Task Perform. & $.46(8.87)^{*}$ \\
$\mathrm{H} 8 \mathrm{~b}$ & Empower't Climate $\rightarrow$ Indiv. Empower't $\rightarrow$ Cont. Perform. & $.23(6.78)^{*}$ \\
$\mathrm{H} 9 \mathrm{a}$ & Empower't Climate $\rightarrow$ Team Empower't $\rightarrow$ Task Perform. & $.50(8.20)^{*}$ \\
$\mathrm{H} 9 \mathrm{~b}$ & Empower't Climate $\rightarrow$ Team Empower't $\rightarrow$ Cont. Perform. & $.24(5.49)^{*}$ \\
\hline & Team-Level Indirect Path & \\
$\mathrm{H} 10 \mathrm{a}$ & Empower't Climate $\rightarrow$ Team Empower't $\rightarrow$ Taskwork & $.57(6.73)^{*}$ \\
$\mathrm{H} 10 \mathrm{~b}$ & Empower't Climate $\rightarrow$ Team Empower't $\rightarrow$ Teamwork & $.35(4.47)^{*}$ \\
\hline
\end{tabular}

NOTE: $\sim \mathrm{p}<0.05 ; \uparrow \mathrm{p}<0.01 ; * \mathrm{p}<0.001$.

${ }^{a}$ Indirect Effects (B') are the product of the unstandardized regression coefficients from the direct relationship between Empowerment Climate \& the Mediator Variable and that between the Mediator Variable and the respective Performance Behaviour

${ }^{\mathrm{b}}$ Values in parenthesis are $\mathrm{z}$ values 